\title{
Parameter identification for a point-supported cross laminated timber slab based on experimental and numerical modal analysis
}

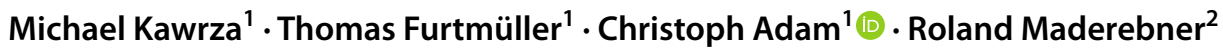

Received: 10 March 2020 / Accepted: 19 November 2020 / Published online: 10 December 2020

(c) The Author(s) 2020

\begin{abstract}
In this paper, the dynamic properties of a point-supported cross-laminated timber slab are studied in order to determine the elastic material parameters on this basis. A detailed experimental modal analysis of the slab with dimensions $16.0 \mathrm{~m} \times 11.0 \mathrm{~m}$ is performed, and seven modes including the natural frequencies, damping ratios and mode shape components at 651 sensor positions are identified. The found mode shapes are complex due to environmental influences that occurred during the twoday measurement campaign. This error is corrected by eliminating these influences. A finite element model of the slab is presented, whose parameters in terms of material properties and boundary conditions are determined by a model updating procedure. Based on the modal properties of the seven experimentally identified modes, an accurate and robust parameter set is obtained, which can be used in further numerical studies of the considered CLT to check serviceability limit criteria.
\end{abstract}

Keywords CLT $\cdot$ Experimental modal analysis $\cdot$ Complex mode shape $\cdot$ Model updating

\section{Introduction}

Since the development of cross laminated timber (CLT) in the early 2000s, timber construction has experienced an enormous gain in importance and has become a serious alternative to concrete and masonry constructions. In general, CLT is a panel of usually 3, 5 or 7 layers - for special purposes even 11 layers - of lamellas (Brandner et al. 2016), which are glued together on their side faces and stacked perpendicular to each other. With CLT elements of some manufacturers even the narrow faces are glued together. The application range of CLT is constantly expanding from single-story to multi-story buildings, which is accompanied by an increase in the span of the structural components. About one hundred years after the architect Le Corbusier developed the Dom-ino system (Schickhofer et al. 2010) (i.e. buildings in frame construction with point-supported reinforced concrete slabs), today buildings in timber construction with point-supported CLT slabs are also being built following

Christoph Adam

christoph.adam@uibk.ac.at

1 University of Innsbruck, Unit of Applied Mechanics, Technikerstr. 13, 6020 Innsbruck, Austria

2 University of Innsbruck, Unit of Timber Engineering, Technikerstr. 13, 6020 Innsbruck, Austria the same idea. An example is the wood-hybrid student residence building at the Campus of the University of British Columbia in Vancouver, which was the tallest mass timber structure in the world at the time it was opened in 2017. The CLT slabs in the 18-story building are point-supported by glued laminated (glulam) columns, which are located at the corners and the edges of each panel. Consequently the resulting column grid is rather narrow.

The economic use of point-supported CLT panels requires however a column grid of at least twice the span width compared to the student residence building in Vancouver. A new type of support system (Maurer et al. 2018; Maderebner 2018) with a steel connection makes these large spans of up to seven meters also possible in mass timber construction with CLT panels. Recently, Muster and Frangi (2020) conducted punching tests on a point-support system without metallic fasteners. In this system, beech plywood panels are used to locally enlarge the cross-section and reinforce the CLT area to increase the load-bearing capacity.

One major advantage of timber constructions over, for example reinforced concrete is its high stiffness-to-weight ratio, which allows comparatively lightweight structures to be built. On the other hand, this makes timber structures made of CLT more prone to vibrations. The design of these structures is therefore generally based on serviceability criteria instead of load-bearing capacity. Vibrations induced 
for instance by inhabitants in buildings, machines, traffic, wind or earthquakes can excite natural frequencies in the human body and subsequently cause general discomfort or even influence breathing movements or muscle contractions (von Gierke and Brammer 2010; Rasmussen 1982). This applies in particular to excitation frequencies up to $10 \mathrm{~Hz}$. At higher frequencies (which are not included in the serviceability criteria), vibrations can lead to annoyance from structure-borne noise, especially in multi-story buildings.

Although the human perception of vibrations is subjective and influenced by a number of parameters (Griffin 1990), some criteria concerning the vibrations of timber floors have been agreed upon in the current regulations. For instance, Eurocode 5 (2019) suggests a lower limit of $8 \mathrm{~Hz}$ for the fundamental frequency of a timber floor to meet serviceability criteria. Additionally, a stiffness criterion to limit deflection and a maximum velocity induced by an impulse of $1 \mathrm{Ns}$ are defined. According to the German standard DIN 1052 (2004), only the maximum deflection is limited. Regardless of the standard used, the results obtained with these criteria are strongly influenced by the assumed material properties of the structural element and the boundary conditions.

As is well known, the material parameters of wood vary in a wide range (Forest Products Laboratory 2010; ÖNORM EN 408 2012), also depending on humidity and temperature. Numerous studies have been carried out to determine the elastic properties of wood-based materials, including structural timber (Görlacher 1984) and wooden panels (Gsell et al. 2007; Gülzow et al. 2008; Berner et al. 2007; Steiger et al. 2012). The vibration behavior of different timber floor systems has also been extensively studied, see for instance Hamm et al. (2010); Schickhofer et al. (2010); Weckendorf et al. (2016); Kreuzinger and Mohr (1999). Popovski et al. (2016) also investigated the dynamic properties of the point-supported floor system in the previously mentioned student residence building in Vancouver with and without openings. In all these studies, the focus is typically on the first natural frequency of the considered slab due to the frequency criteria mentioned above. One common result is that the difference between the predicted fundamental frequency according to various standards and rules and the actual experimentally identified value is quite large. The authors attribute this to the strongly dispersing material parameters and to the influence of the boundary conditions.

In the present paper, the dynamic behavior of a pointsupported CLT slab is investigated. In contrast to previous studies, a detailed experimental modal analysis (EMA) is performed to identify a number of natural frequencies, corresponding modal damping ratios and mode shapes. This experimental data set is used to adjust a finite element (FE) model of the slab by means of model updating (Friswell and Mottershead 1995). The goal of this study is (i) to obtain insight into the dynamic behavior of the point-supported
CLT slab supported by the novel star-shaped steel connector (Maurer et al. 2018; Maderebner 2018), (ii) to identify influence of the boundary conditions on the slab dynamics, and (iii) to determine a set of representative and robust material properties that can be used to predict reliably the response of CLT structures with different setups in terms of geometry, spans and floor constructions by FE analyses. Ultimately, the serviceability of such point-supported CLT structures can be assessed more realistically.

The paper is organized as follows: In section 2, the test specimen is described. The theoretical foundations of the applied methods, both experimental and numerical, are outlined in section 3. The results are presented in section 4, and section 5 contains the conclusions of the study.

\section{Test specimen}

The test specimen is a point-supported flat slab, which is composed of seven CLT panels without joists, see Figs. 1 and 2. The CLT panels are made of spruce boards of strength class C24 (ÖNORM EN 338 2016), with a seven layer setup of thickness 20-40-20-40-20-40-20 mm. The top layer is aligned parallel to the longitudinal direction of the slab. The overall dimensions of the slab are $16.0 \mathrm{~m} \times 11.0 \mathrm{~m} \times 0.2 \mathrm{~m}$. The slab rests on 12 columns with a grid of $5.0 \mathrm{~m} \times 5.0 \mathrm{~m}$, see Fig. 2. The inner point-supports, visible in Fig. 1, are reinforced by a star-shaped steel connector (Maurer et al. 2018) on the surface. 196 steel plates (dimensions $0.8 \mathrm{~m}$ x $0.18 \mathrm{~m} \times 0.005 \mathrm{~m}$ ) cast in epoxy resin connect the seven CLT panels, which are arranged between the panel joints as depicted in Fig. 2. As the test specimen is set up in an outdoor area, a tent construction protects the structure from the weather. The aluminum columns of the tent construction are bolted to the slab directly above the 10 outer columns that support the slab. The influence of the tent on the dynamic properties is therefore negligible. The ten outer columns and two inner columns (i.e. below the steel connectors) with the dimensions $0.2 \mathrm{~m} \times 0.2 \mathrm{~m} \times 1.0 \mathrm{~m}$ are fixed on prefabricated

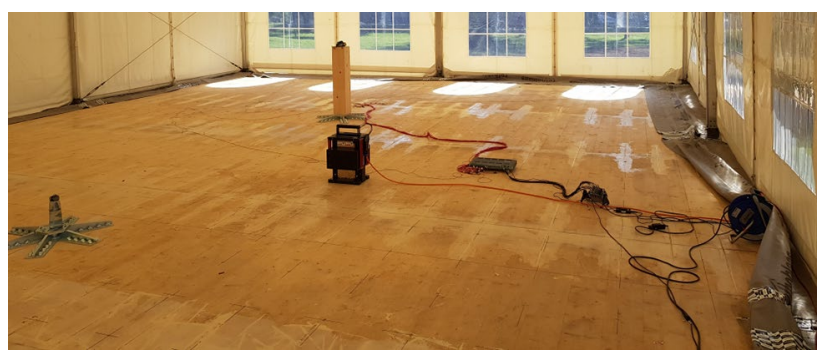

Fig. 1 Photo of the slab with star-shaped steel connectors for the inner point-supports; test setup 


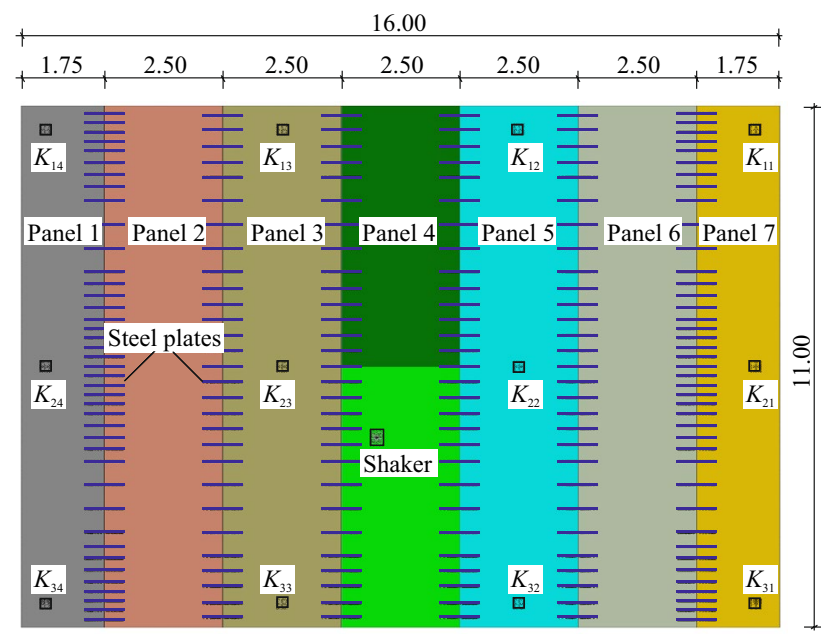

Fig. 2 Sketch of the slab composed of seven individual panels connected by steel plates; equivalent stiffness coefficients of the pointsupports $K_{i j}$. Dimensions in [m]

foundations consisting of concrete blocks with the dimensions $0.75 \mathrm{~m} \times 0.75 \mathrm{~m} \times 0.50 \mathrm{~m}$.

\section{Methods}

As outlined in section 1, one aim of this study is to identify all parameters needed for a reliable FE model of the investigated slab. To this end, a model updating procedure is created within the MATLAB environment (MATLAB 2019), as shown schematically in Fig. 3, which triggers FE simulations in ABAQUS (Abaqus 2015). The basis of this procedure is the formulation of an optimization problem, in which the outcomes of the numerical model are compared with experimental data. By adjusting the model parameters, the error between the two data sets is minimized, resulting in

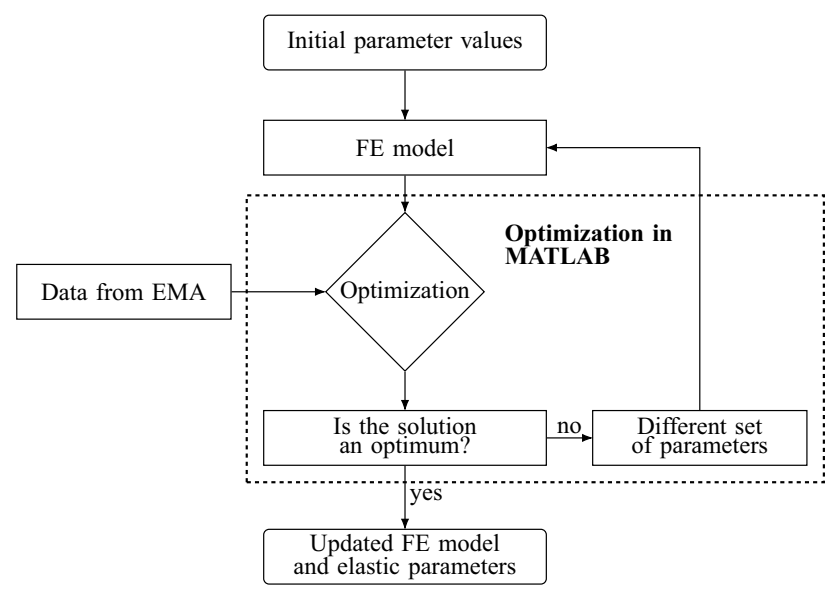

Fig. 3 Model updating procedure optimal parameters for the FE model. Here, the Nelder-Mead simplex algorithm implemented in the MATLAB function fminsearch (MATLAB 2019) is used for optimization. As this study deals with the dynamic properties of the CLT slab, modal data are employed to formulate the objective function to be minimized. In particular, the mean error of the natural frequencies $\epsilon_{E F}$ and the mode shapes $\epsilon_{M S}$, defined as

$\epsilon_{E F}=\frac{1}{n} \sum_{i=1}^{n} \epsilon_{E F}^{(i)}, \quad \epsilon_{E F}^{(i)}=\frac{\left|f_{i}^{F E M}-f_{i}^{E M A}\right|}{f_{i}^{E M A}}$

$\epsilon_{M S}=\frac{1}{n} \sum_{i=1}^{n} \epsilon_{M S}^{(i)}, \epsilon_{M S}^{(i)}=1-\mathrm{M}\left(\{\phi\}_{i}^{F E M},\{\phi\}_{i}^{E M A}\right)$

serve as objective functions. In Eq. (1), $f_{i}^{F E M}$ is the $i$ th numerically predicted natural frequency, and $f_{i}^{E M A}$ the experimental counterpart. The variable $n$ denotes the number of considered modes. In Eq. (2), $\mathrm{M}\left(\{\phi\}_{i}^{F E M},\{\phi\}_{i}^{E M A}\right)$ represents the modal assurance criterion (MAC) value between the $i$ th numerically computed and the $i$ th experimentally identified mode shape $\{\phi\}_{i}^{F E M}$ and $\{\phi\}_{i}^{E M A}$, respectively (Allemang 2003). Basis of the model updating procedure is an appropriate set of experimental modal data. In this study, an EMA is conducted to obtain these data as described below.

\subsection{Experimental modal analysis (EMA)}

The structure is excited by an electrodynamic shaker of type APS 400 with an additional reaction mass of type APS 0412, operated with a power amplifier type APS 145. The shaker, whose position is shown in Fig. 4, has a total mass of $105 \mathrm{~kg}$ composed of $70 \mathrm{~kg}$ static mass and $35 \mathrm{~kg}$ dynamic active

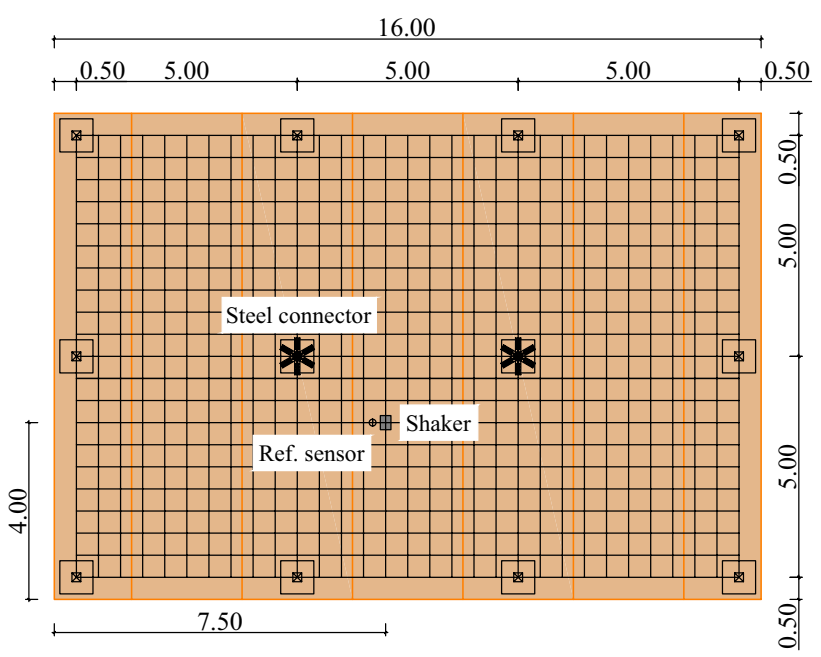

Fig. 4 Measurement grid, column grid, positions of the shaker and the reference sensor. Dimensions in [m] 
mass. The excitation signal is a linear sweep (chirp) from $6 \mathrm{~Hz}$ to $50 \mathrm{~Hz}$ with a duration of 120 seconds, including an initial signal increase and a final signal decay period of ten seconds each.

The dynamic response is recorded at 651 surface points of the CLT slab by piezoelectric accelerometers type Brüel\&Kjær 4508 B powered by a conditioning amplifier type Brüel\&Kjær 2694. The large number of measuring points helps to detect possible local effects, for example through the connection of the CLT plates or through the supports. The measurement grid (grid length $0.5 \mathrm{~m}$ ) is depicted in Fig. 4. Since nine acceleration sensors are available, a total of 73 individual measurements must be taken to record the response of the entire plate. In addition, a reference sensor of type Brüel\&Kjær 8344 records the response of a stationary point of the slab near the shaker during each measurement, see Fig. 4. The data acquisition is performed by a National Instruments (NI) cDAQ module with NI 9234 A/D converters, which is controlled by a MATLAB program.

For each of the 73 setups, the sweep is repeated four times, yielding a total measurement time of 480 seconds per test. This adds up to a net measuring time of almost 10 hours for all measurements. Including the time needed to change sensors between tests, the total measurement time performed from September 18 to 19, 2019 was two days.

To compensate for resonance effects, the input voltage signal must be adjusted to excite all frequencies in the considered frequency range equally. This is achieved by measuring the acceleration at the dynamic active oscillating mass during the sweep and iterative adjustment of the input voltage signal, as shown in the upper part of Fig. 5. The power spectral density (PSD) of the resulting acceleration signal recorded at the shaker mass, which is depicted in the lower part of this figure, shows the desired flat spectrum in
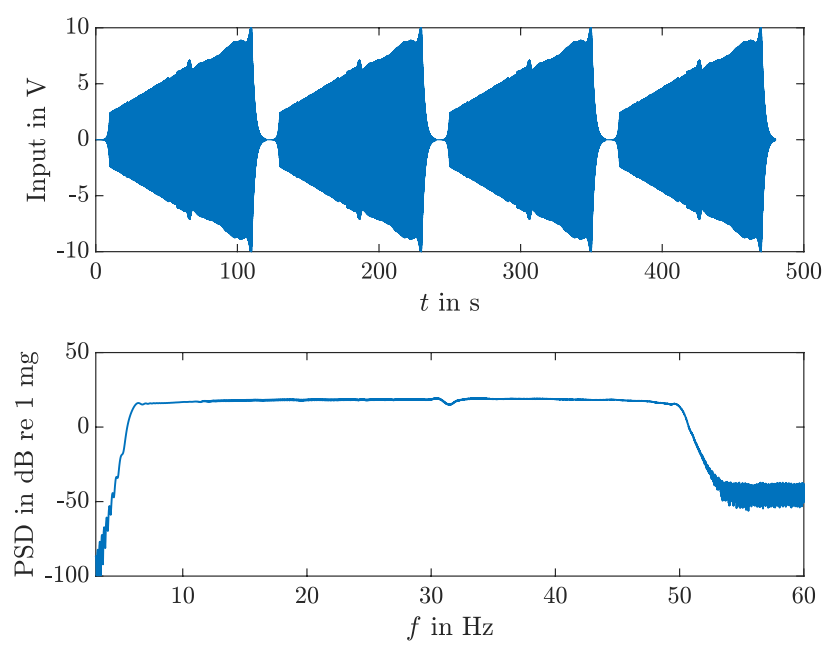

Fig. 5 Top: Voltage input signal over time. Bottom: PSD of input signal the frequency range of interest without any valleys at resonances. Note that for the translational motion of the rigid mass block accelerated by the shaker, the input force is equal to the mass times acceleration.

\subsection{Finite element (FE) model}

The FE model to be updated with the experimental data is created in the FE framework ABAQUS. To facilitate efficient computation, the CLT slabs are discretized in ABAQUS by shell elements of type S8R, which are based on the first order shear deformation theory (FSDT) (Reddy 2004). The shell element S8R uses quadratic interpolation functions and reduced numerical integration. This FSDT-based element is chosen because recently it has been shown (Furtmüller and Adam 2020) that this plate theory is sufficiently accurate in the lower frequency range under consideration to capture the deformation in CLT components under bending vibrations if the shear correction factors are chosen accordingly. In the present study, the relations proposed in Whitney (1973) are used to compute the shear correction factors, which depend on the material properties and the layer setup. The linear elastic constitutive relations given in terms of general shell stiffness matrices can be directly entered into ABAQUS. For planar laminates with a symmetric layer setup, as is the case with the present seven-layer CLT slab, only the bending stiffness matrix $[D]$ and the shear stiffness matrix $[K]$ need to be specified, which control the relationship between the section moments and the transverse forces, and between the kinematic quantities (curvatures and transverse shear strains). The components of these matrices are obtained from the elastic properties of the layers and the layer thicknesses according to the relationships given in Reddy (2004). The components of the initial plate stiffness matrices are computed assuming that the side and narrow faces are glued together. In the present study, a simplified linear-elastic orthotropic material behavior is assumed for the individual wood layers of the CLT slab in accordance with the specifications in the standards (ÖNORM EN 338 2016). That is, the material parameters differ only parallel to the grain and perpendicular to the grain. These material parameters are the moduli of elasticity in parallel $E_{1}$ and in perpendicular direction $E_{2}\left(=E_{3}\right)$ as well as the Poisson ratios $v_{12}\left(=v_{13}\right)$ and $v_{23}$, and lastly the shear modulus $G_{12}\left(=G_{13}\right)$ and the rolling shear modulus $G_{23}$.

The steel plates connecting the individual plates are modeled with beam elements (type B32), which are tied to the corresponding shell elements of the plates. Each flexible support is modeled by one additional node, which is coupled to nodes in the area of the supports by means of kinematic constraints. The additional nodes are located below the mid-surface of the shell. Thus, by varying the distance of the nodes to the mid-surface, a hinged support 
with a certain rotational stiffness can be modeled. The flexibility of the supporting columns and the subsoil is taken into account by vertical springs, denoted in Fig. 2 as $K_{i j}$ $(i=1,2,3 ; j=1,2,3,4)$. To determine the effective spring stiffness of the soil, the cone model specified in Wolf (1994) is used.

The shaker mass is taken into account by lumped masses distributed evenly over its basic dimensions. The resulting FE model consists of 22,740 elements with 398,262 degrees of freedom.

\section{Results}

\subsection{Experimental modal analysis}

\subsubsection{Modal parameter estimation (MPE)}

The least squares complex frequency (LSCF) estimator (Verboven 2002) is used to estimate the modal parameters, i.e. the natural frequencies, damping ratios and mode shapes, from the 651 frequency response functions (FRFs) of the single input - multiple output system. This frequency domain modal parameter estimation (MPE) method yields more accurate stabilization diagrams (Cauberghe et al. 2005) when compared to the widely used least squares complex exponential (LSCE) time domain method (Ewins 2000). The criteria for a pole to be considered stable utilized in this study are

$\Delta f_{i}^{E M A}=\frac{\left|f_{i,(m-1)}^{E M A}-f_{i,(m)}^{E M A}\right|}{f_{i,(m-1)}^{E M A}} 100 \leq 1 \%$

$\Delta \zeta_{i}=\frac{\left|\zeta_{i,(m-1)}-\zeta_{i,(m)}\right|}{\zeta_{i,(m-1)}} 100 \leq 10 \%$

$\Delta \phi_{i}=\mathrm{M}\left(\Re\left(\{\phi\}_{i,(m-1)}\right), \mathfrak{R}\left(\{\phi\}_{i,(m)}\right)\right) \quad \geq 0.95$

$\Delta f_{i}^{E M A}$ and $\Delta \zeta_{i}$ in Eqs (3) and (4) are thus the relative changes of the $i$ th natural frequency $f_{i}^{E M A}$ and the $i$ th damping ratio $\zeta_{i}$, respectively, resulting from the poles (Ewins 2000) between two model orders $m-1$ and $m . \Delta \phi_{i}$ in Eq. (5) is the MAC value of the real part $\Re$ of the $i$ th mode shape $\{\phi\}_{i}$.

Figure 6 shows the resulting stabilization diagram of the CLT slab for an expected number of modes (model order) ranging from 10 to 50 in the frequency range 6 to $50 \mathrm{~Hz}$. Circular markers indicate stable poles, cross-shaped markers unstable ones, and triangles new poles. Additionally, the mean FRF is shown by a solid line to facilitate the distinction between physical and non-physical poles. As can be seen, the fundamental natural frequency for this structure is

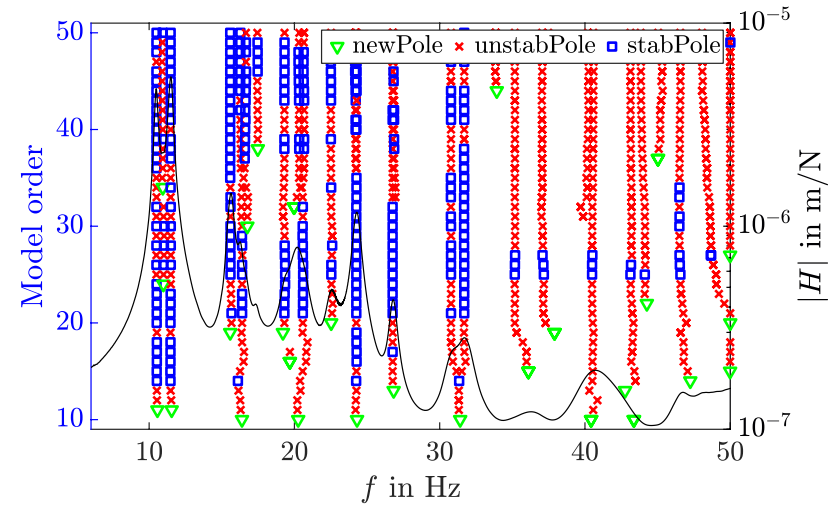

Fig. 6 Stabilization diagram of the slab resulting from the LSCF method

Table 1 Experimentally identified natural frequencies $f_{i}^{E M A}$ and damping ratios $\zeta_{i}$, $i=1, \ldots, 7$

\begin{tabular}{lll}
\hline Mode $(i)$ & $f_{i}^{E M A}[\mathrm{~Hz}]$ & $\zeta_{i}[\%]$ \\
\hline 1 & 10.51 & 3.23 \\
2 & 11.49 & 2.22 \\
3 & 15.60 & 1.66 \\
4 & 22.52 & 2.57 \\
5 & 24.26 & 1.50 \\
6 & 26.76 & 1.25 \\
7 & 31.69 & 2.00 \\
\hline
\end{tabular}

$10.51 \mathrm{~Hz}$, and various stable poles indicate a series of additional higher modes in the depicted frequency range. However, for FE model updating only the seven modes, whose frequencies and damping coefficient are listed in Table 1, are used. For the ignored modes, the mode shapes could not be unambigously identified. Therefore, the subscript $i$ in the variables of Table 1 does not necessarily indicate the actual mode but is just a number to differentiate the modes used in model updating. The natural frequency of the highest considered mode is $31.69 \mathrm{~Hz}$, and the damping ratios vary between 1.25 and $3.23 \%$, see Table 1 .

Figure 7 shows the real parts of the modal displacements of the considered modes. The fundamental mode illustrated in Fig. 7(a) is a bending mode with a distinct nodal line along the slab length. Although the geometry is completely symmetrical, this mode shape has a relatively strong longitudinal asymmetry with larger modal amplitudes in the right field of the slab. The additional mass due to the shaker seems to mainly influence the second mode shape, Fig. 7(b), with the largest modal amplitudes being in the field where the shaker is positioned. With increasing natural frequency (Fig. 7(c)-(g)), the asymmetry in the mode shapes decreases. 
(a)

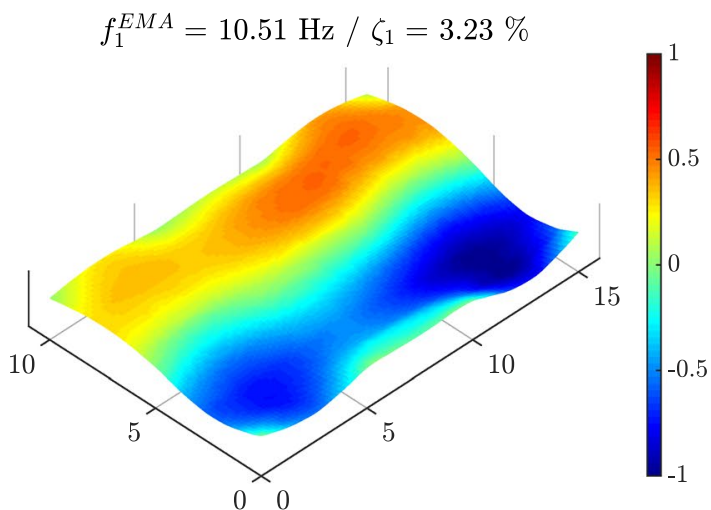

$f_{3}^{E M A}=15.60 \mathrm{~Hz} / \zeta_{3}=1.66 \%$

(c)
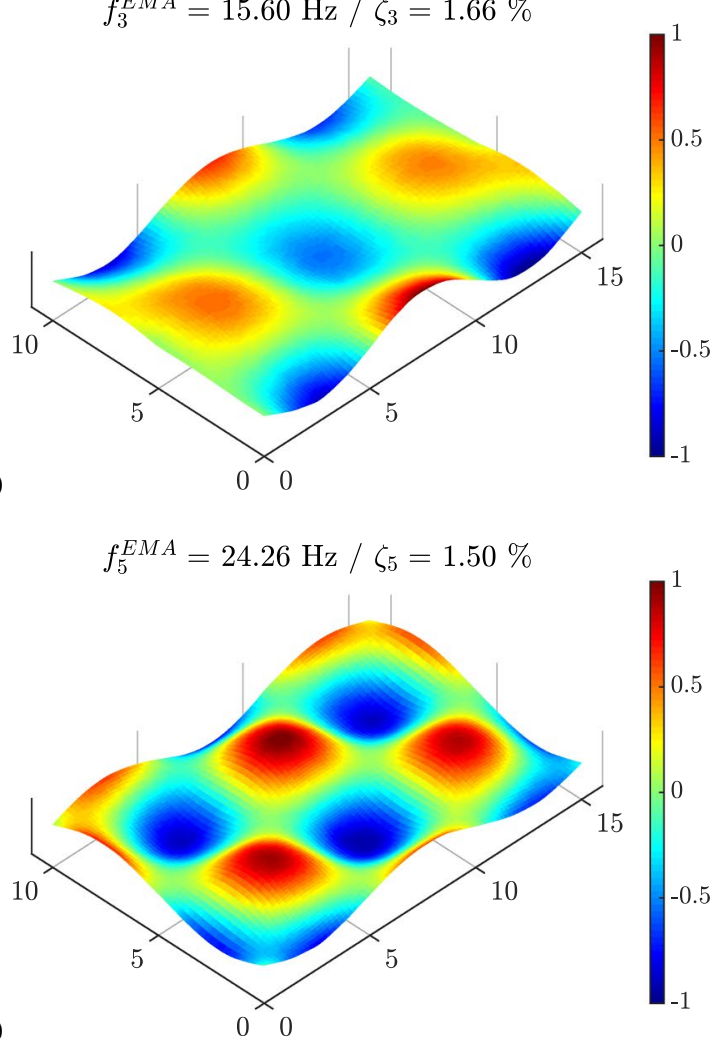

(e)

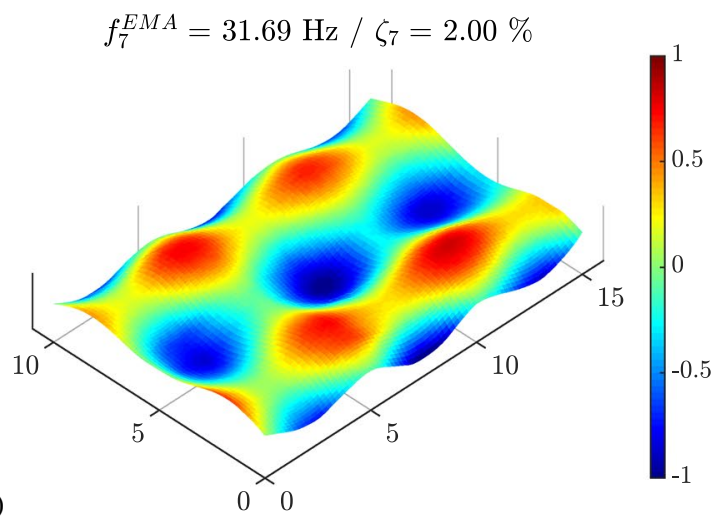

(g) (b)

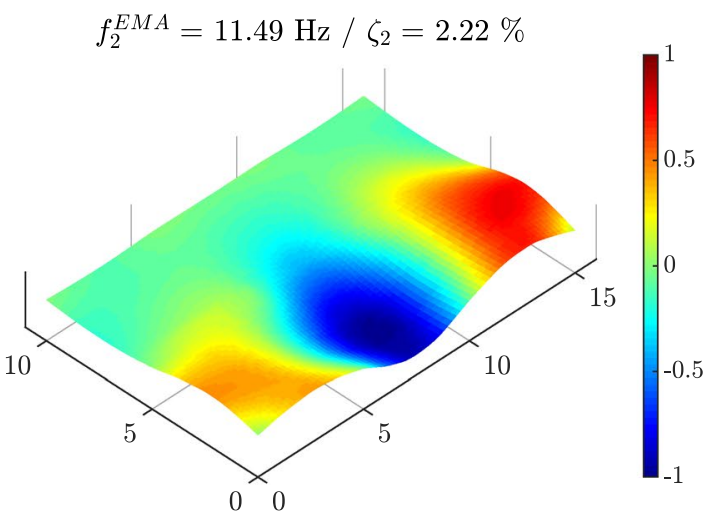

(d)

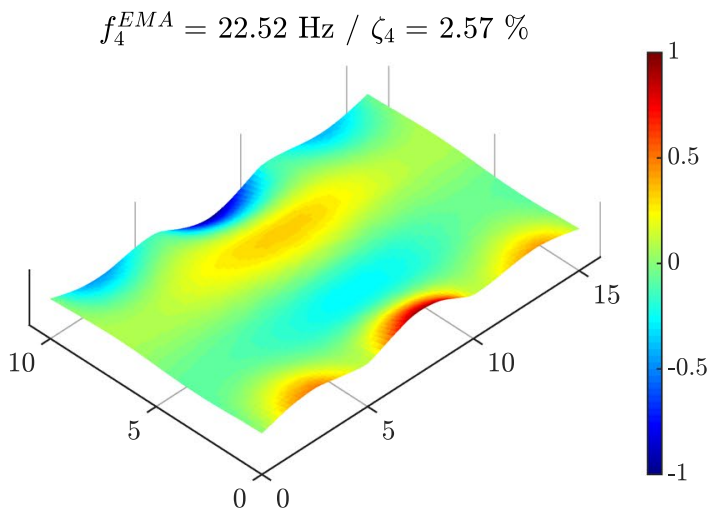

$f_{6}^{E M A}=26.76 \mathrm{~Hz} / \zeta_{6}=1.25 \%$

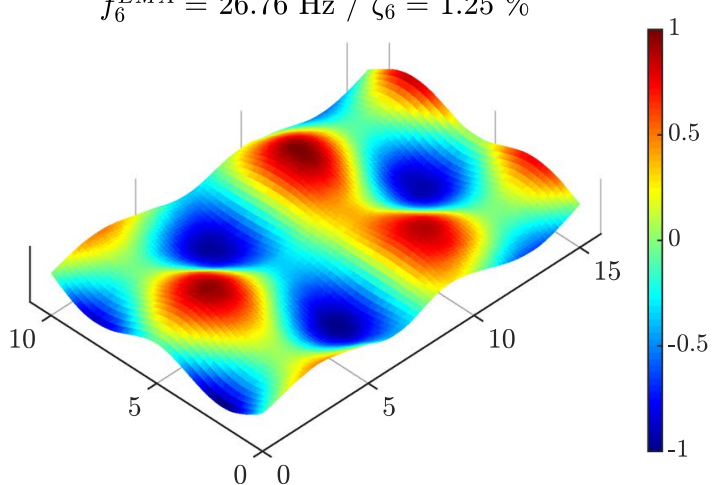

Fig. 7 Identified mode shapes 1 to 7, corresponding natural frequencies and damping ratios 


\subsubsection{Complex mode shapes}

The MPE provides typical mode shapes, which to a certain extent also have an imaginary part. From a mechanical point of view, complex mode shapes occur with non-proportionally damped tested specimen. However, if damping is low - as is the case for the considered CLT slab - this influence is small and the imaginary part of the mode shapes should be negligible.

In the following, the mean phase correlation (MPC) is used to quantify the imaginary part of the mode shapes. For the $i$ th mode shape vector $\{\phi\}_{i}$, the MPC is defined as (Phillips and Allemang 2014)

$\mathrm{MPC}_{i}=1-\frac{\left\|\mathfrak{\Im}\left(\{\phi\}_{i}\right)\right\|}{\left\|\mathfrak{R}\left(\{\phi\}_{i}\right)\right\|}$

where $\mathfrak{R}$ and $\mathfrak{I}$ denote the real and imaginary part of $\{\phi\}_{i}$. According to this definition, an MPC value close to one represents a real (normal) mode. In Table 2, variable $\mathrm{MPC}_{i}^{(0)}$ indicates MPC values with mode shape vectors obtained from MPE. Since all identified mode shapes have MPC values below $0.9(90 \%)$, the imaginary part is rather large, which is in contradiction to the above physical facts.

The relatively large imaginary part in the identified mode shapes can be attributed to the violation of a condition inherently implied in modal analysis, namely that the tested structure is strictly speaking a time-varying system. The temporal variance of the plate under consideration, which is exposed to environmental influences, is due to the fact that the measurements were not taken at one time instant but over two days. Since in each of these 73 individual measurements the response was additionally recorded with a reference sensor that was located stationary in close proximity to the shaker, the evaluation of this response can show this temporal system variance. To illustrate this, Fig. 8 shows a spectrogram of the frequency response function (FRF) of the sensor position in a range from 10 to $11 \mathrm{~Hz}$ (i.e., in the vicinity of the first identified natural frequency) as a function of the recording time. The maximum of the spectrogram corresponds to the first natural frequency. This maximum is not stationary at

Table 2 MPC values before (superscript 0) and after (superscript $c$ ) correction

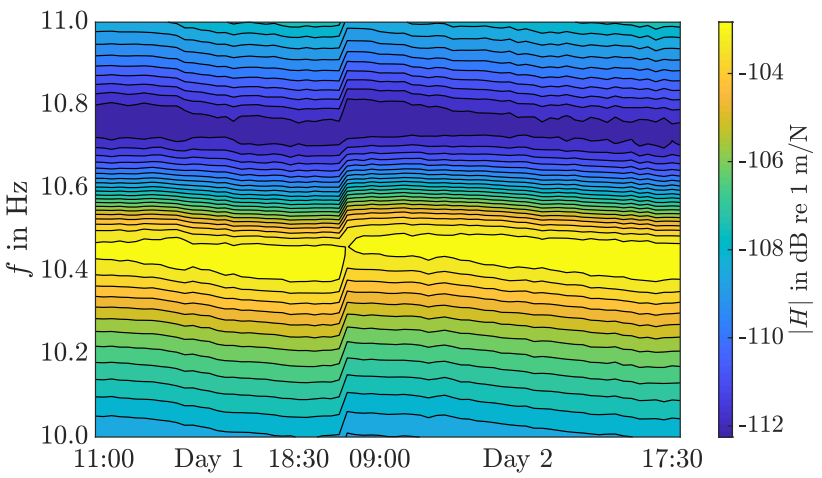

Fig. 8 Spectrogram in the vicinity of the first natural frequency with time of each measurement

a value of $f$, but depends on the time of day. During the day, the natural frequency tends to decrease, while between the last measurement on day 1 and the first measurement in the morning of day 2 a jump of about $0.05 \mathrm{~Hz}$ can be observed. It is reasonable to assume that particularly the effect of the ambient temperature disturbs the identified modal parameters, as discussed later. The natural frequencies and damping ratios specified in Table 1 are therefore "temporal mean values" of the time-varying slab system. Since mode shapes are obtained during MPE in a second step after poles have been determined, the use of these mean poles consequently results in complex quantities.

To compensate for this effect on the mode shapes, each of the 73 measurements is subsequently treated independently. That is, the vector $\{\phi\}_{i}$ for mode $i$ is composed of 73 subsets $\{\varphi\}_{i}^{(k)}$, with $k=1,2, \ldots 73$. For each subset separately, the imaginary part is minimize by means of a central axis rotation (CAR) (Phillips and Allemang 2014). In the first step, a singular value decomposition (svd) is performed (Phillips and Allemang 2014),

$$
\begin{aligned}
{[U, \Sigma, V]=} & \operatorname{svd}\left(\left[\mathfrak{\Im}\left(\{\varphi\}_{i}^{(k)}\right) \mathfrak{R}\left(\{\varphi\}_{i}^{(k)}\right)\right]^{T}\right. \\
& {\left.\left[\mathfrak{J}\left(\{\varphi\}_{i}^{(k)}\right) \mathfrak{R}\left(\{\varphi\}_{i}^{(k)}\right)\right]\right) }
\end{aligned}
$$

which yields the matrix $[V] \in \mathbb{R}^{2 \times 2}$. With the components $V_{22}$ and $V_{12}$ of this matrix [V], the mean angle of mode shape subset $\{\varphi\}_{i}^{(k)}$ in the complex plane (Phillips and Allemang 2014),

\begin{tabular}{lll}
\hline Mode (i) & $\mathrm{MPC}_{i}^{(0)}$ & $\mathrm{MPC}_{i}^{(c)}$ \\
\hline 1 & 0.81 & 0.95 \\
2 & 0.86 & 0.96 \\
3 & 0.88 & 0.96 \\
4 & 0.89 & 0.93 \\
5 & 0.87 & 0.96 \\
6 & 0.86 & 0.94 \\
7 & 0.74 & 0.87 \\
\hline
\end{tabular}

$\delta_{i}^{(k)}=\tan ^{-1}\left(-\frac{V_{22}}{V_{12}}\right)$

is computed. The rotation by this angle according to (Phillips and Allemang 2014)

$\{\bar{\varphi}\}_{i}^{(k)}=\{\varphi\}_{i}^{(k)} \exp \left(-j \delta_{i}^{(k)}\right)$ 


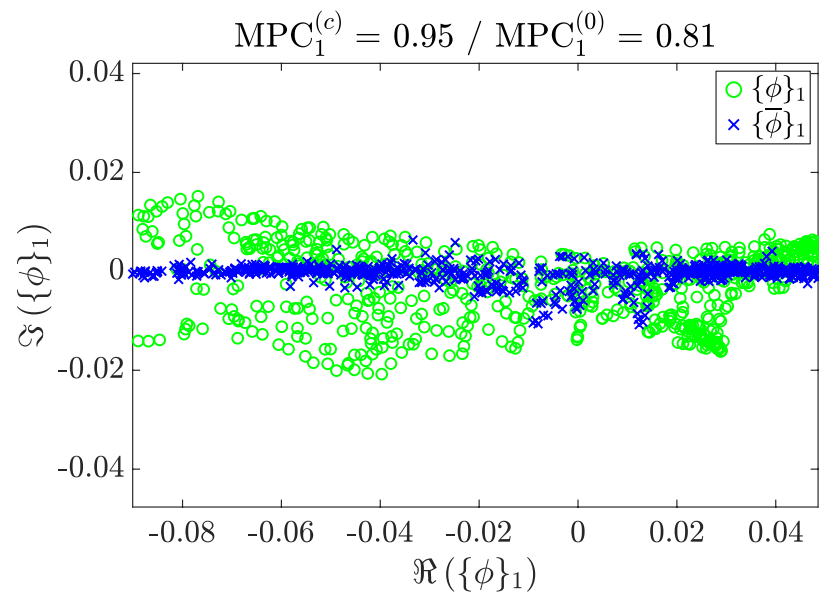

Fig. 9 Real-imaginary scatter plot of each component of mode 1 before (circular markers) and after correction (cross-shaped markers)

then minimizes the imaginary part for $\{\varphi\}_{i}^{(k)}$. In Eq. (9), $j$ denotes the imaginary unit.

Figure 9 illustrates the results of this piece-wise rotation for mode shape 1. Circles represent the 651 components of mode shape vector $\{\phi\}_{1}$ in the complex plane. As specified in Table 2, the MPC value for this vector is 0.81. After correction, the modified vector $\{\bar{\phi}\}_{1}$ represented by crossshaped markers has an MPC value of 0.95 . As can be read from Table 2, the correction significantly reduces the imaginary part of all seven identified mode shapes. The corrected mode shapes (depicted in Fig. 7) can therefore be regarded as almost real modes, as the relatively low damping of the system suggests.

As discussed above, it is expected that the ambient temperature is the dominant disturbance effect, which leads to a time-variance of the tested system, particularly of the soil where the foundations of the supporting columns are embedded. Therefore, in Fig. 10 the ambient temperature recorded at a nearby weather station is depicted, showing a temperature range from $14^{\circ} \mathrm{C}$ to $20^{\circ} \mathrm{C}$ during the measurement campaign. Additionally, rotation angles $\delta_{1}^{(k)}$, normalized with the median of the function used for the correction of the first mode shape are shown. Apart from the evening measurements of day 2, a close correlation of both timehistories is observed. As the ambient temperature increases, the angles $\delta_{1}^{(k)}$ also increase and vice versa. The temperature jump between the measurements on the first and second day is also visible in the correction angles.

However, the observed correlation is not as pronounced for the other identified mode shapes as shown in Fig. 11, where the angles $\delta_{i}^{(k)}$ normalized with the medians of the associated functions are depicted for modes 2 to 7 .

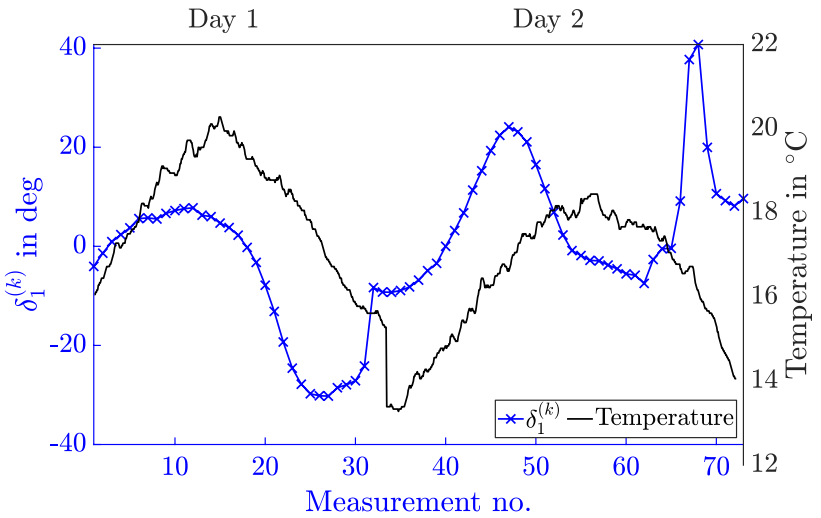

Fig. 10 Correction angle $\delta_{1}^{(k)}$ for mode shape 1 with respect to the individual measurements, and corresponding ambient temperature

\subsection{Numerical simulations}

Based on this set of seven identified modes, the parameters for the FE model are determined in the following. The first step is to define the parameters to be optimized within the framework of the model update procedure. The challenge here is that the FE model should represent the structure as accurately as possible, while the number of parameters should be as low as possible.

\subsubsection{Parameters for model updating}

Material properties of the CLT panels are obvious candidates for the model updating parameters. As initial values, the moduli of elasticity in parallel $E_{1}$ and in perpendicular direction $E_{2}$ as well as the shear modulus $G_{12}$ are taken from standards for spruce with strength class C24 (ÖNORM EN 338 2016). In addition, Niemz and Sonderegger (2017) provide values for the shear modulus $G_{23}$ in a range of $33 \mathrm{MPa}$ to $66 \mathrm{MPa}$, while ÖNORM B 1995-1-1 (2019) specifies $G_{23}$ with a value of $65 \mathrm{MPa}$. Since preliminary studies have shown that the value of Poisson ratios $v_{12}$ and $v_{23}$ do not affect the results of modal analysis, they have been set to a fixed value of 0.4 , and are thus not parameters to be optimized. In summary, the chosen initial optimization values for the orthotropic elasticity parameters of the CLT layers are listed in the first part of Table 3.

The average density of timber classified in strength class C24 is $\rho=420.0 \mathrm{~kg} / \mathrm{m}^{3}$ according to ÖNORM EN 338 (2016), while Niemz and Sonderegger (2017) report values up to $500 \mathrm{~kg} / \mathrm{m}^{3}$. Based on the mean weight of several test CLT samples (Furtmüller et al. 2019), an initial density of $\rho=488.0 \mathrm{~kg} / \mathrm{m}^{3}$ is chosen.

As shown in section 4.1, the identified mode shapes are not symmetrical. To take this effect into account in the FE model, each of the seven panels of the slab (see Fig. 2) is 

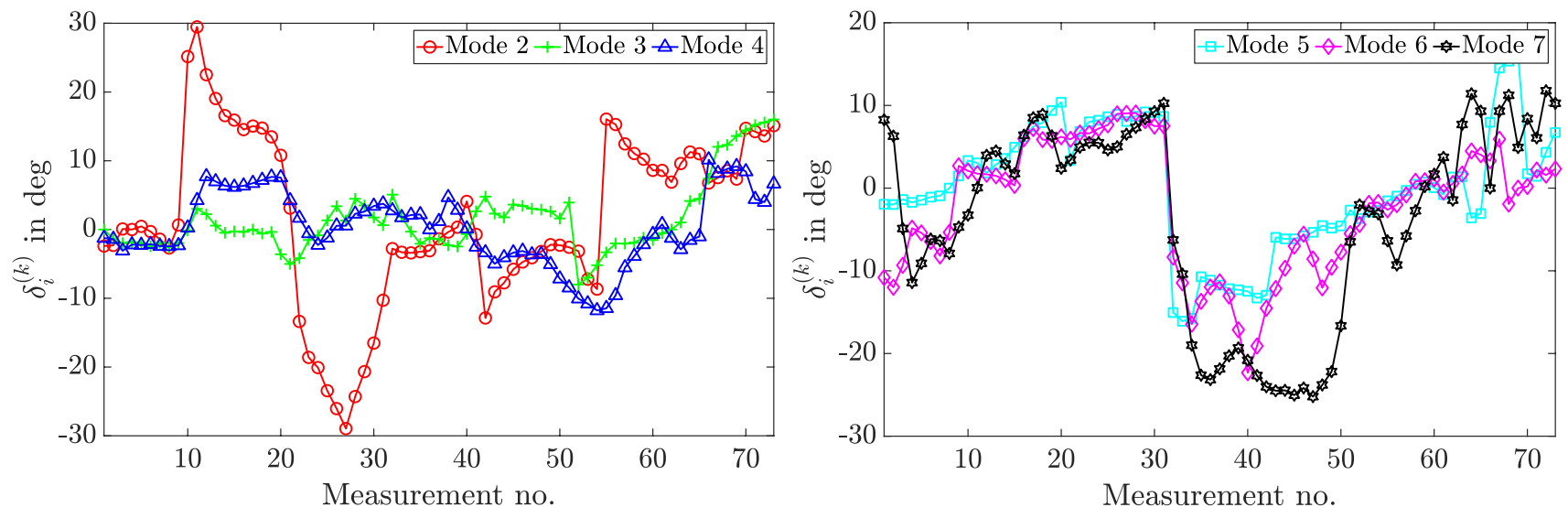

Fig. 11 Correction angles for mode shapes $i=2,3,4$ (left graphs) and $i=5,6,7$ (right graphs) with respect to the individual measurements

Table 3 Mean values $\mu$ and standard deviation $\sigma$ for models with a different number of optimized parameters $(l=1, \ldots, 7 ; i=1,2,3$; $j=1,2,3,4)$

\begin{tabular}{|c|c|c|c|c|}
\hline No. of parameters & Parameter & Unit & $\mu$ & $\sigma$ \\
\hline \multirow[t]{7}{*}{42 (initial values) } & $E_{1}^{l}$ & {$[\mathrm{MPa}]$} & 11,000 & \\
\hline & $G_{12}^{l}$ & {$[\mathrm{MPa}]$} & 690 & \\
\hline & $G_{23}^{l}$ & {$[\mathrm{MPa}]$} & 50.0 & \\
\hline & $\rho^{l}$ & {$\left[\mathrm{~kg} / \mathrm{m}^{3}\right]$} & 488 & \\
\hline & $K_{i j}$ & {$[\mathrm{MN} / \mathrm{m}]$} & 50.0 & \\
\hline & $z_{\text {in }}$ & {$[\mathrm{m}]$} & 0.05 & \\
\hline & $z_{\text {out }}$ & {$[\mathrm{m}]$} & 0.05 & \\
\hline \multirow[t]{7}{*}{42} & $E_{1}^{l}$ & {$[\mathrm{MPa}]$} & 12,426 & 1,320 \\
\hline & $G_{12}^{l}$ & {$[\mathrm{MPa}]$} & 676 & 108 \\
\hline & $G_{23}^{l}$ & {$[\mathrm{MPa}]$} & 50.8 & 10.9 \\
\hline & $\rho^{l}$ & {$\left[\mathrm{~kg} / \mathrm{m}^{3}\right]$} & 451 & 25.2 \\
\hline & $K_{i j}$ & {$[\mathrm{MN} / \mathrm{m}]$} & 50.3 & 8.79 \\
\hline & $z_{\text {in }}$ & {$[\mathrm{m}]$} & 0.0594 & \\
\hline & $z_{\text {out }}$ & {$[\mathrm{m}]$} & 0.0277 & \\
\hline \multirow[t]{7}{*}{24} & $E_{1}$ & {$[\mathrm{MPa}]$} & 12,340 & \\
\hline & $G_{12}$ & {$[\mathrm{MPa}]$} & 814 & \\
\hline & $G_{23}$ & {$[\mathrm{MPa}]$} & 60.2 & \\
\hline & $\rho^{l}$ & {$\left[\mathrm{~kg} / \mathrm{m}^{3}\right]$} & 468 & 23.4 \\
\hline & $K_{i j}$ & {$[\mathrm{MN} / \mathrm{m}]$} & 51.1 & 8.00 \\
\hline & $z_{\text {in }}$ & {$[\mathrm{m}]$} & 0.0558 & \\
\hline & $z_{\text {out }}$ & {$[\mathrm{m}]$} & 0.0256 & \\
\hline \multirow[t]{7}{*}{31} & $E_{1}$ & {$[\mathrm{MPa}]$} & 12,577 & \\
\hline & $G_{12}$ & {$[\mathrm{MPa}]$} & 829 & \\
\hline & $G_{23}$ & {$[\mathrm{MPa}]$} & 54.8 & \\
\hline & $\rho_{U / L}^{l}$ & {$\left[\mathrm{~kg} / \mathrm{m}^{3}\right]$} & 476 & 34.6 \\
\hline & $K_{i j}$ & {$[\mathrm{MN} / \mathrm{m}]$} & 47.6 & 11.2 \\
\hline & $z_{\text {in }}$ & {$[\mathrm{m}]$} & 0.0911 & \\
\hline & $z_{\text {out }}$ & {$[\mathrm{m}]$} & 0.0266 & \\
\hline
\end{tabular}

assigned a set of elastic parameters, $E_{1}^{l}, G_{12}^{l}, G_{23}^{l}$ and $\rho^{l}$. With $l=1 \ldots 7$ this gives in total 28 parameters. Due to the small influence of modulus of elasticity $E_{2}$ on the response compared to $E_{1}$, this material property is not used as an additional parameter, but set to $E_{2}=E_{1} / 30$, depending on parameter $E_{1}$.

Another set of parameters results from the point-supports of the slab modeled by linear elastic springs, as described in section 3.2. The foundations of the columns are prefabricated cuboids made of concrete, placed on an open field without compacting the soil beforehand, see section 2. It is therefore to be expected that the soil stiffness varies between the supports, which results in 12 individual spring stiffnesses (one for each support) as further parameters to be optimized. Finally, as mentioned in section 3.2, a certain amount of rotational stiffness can be assigned to the supports by adjusting the position of the support nodes coupled to the slab with respect to the plate mid-surface. These node distances are two further optimization parameters, i.e. the distance $z_{\text {out }}$ for the ten outer supports and the distance $z_{\text {in }}$ for the two inner supports. Thus, the star-shaped steel connectors are indirectly considered, as described in section 2 . This gives for the initial study a total of 42 optimization parameters.

\subsubsection{Sensitivity analysis and parameter reduction}

A sensitivity analysis is performed to quantify the influence of each parameter on the modal properties of the slab, and subsequently to eliminate parameters with minor impact. Table 4 summarizes these results by listing relative errors for the natural frequencies, $\epsilon_{E F}^{(i)}$, and mode shapes, $\epsilon_{M S}^{(i)}$, for each mode separately, see Eq. 1 and 2, while in the second, third and fourth part of Table 3, the optimized parameters are displayed. Additionally, the mean $\mu$ and the standard deviation $\sigma$ of selected material properties of the individual CLT panels, i.e. $E_{1}^{l}, G_{12}^{l}, G_{23}^{l}$ and $\rho^{l}$, the individual support 
Table 4 Errors obtained after model updating with a different number of parameters

\begin{tabular}{|c|c|c|c|}
\hline No. of parameters & Mode $(i)$ & $\epsilon_{E F}^{(i)}[\%]$ & $\epsilon_{M S}^{(i)}[\%]$ \\
\hline \multirow[t]{8}{*}{42} & 1 & 3.20 & 3.85 \\
\hline & 2 & 2.32 & 17.78 \\
\hline & 3 & 0.00 & 6.07 \\
\hline & 4 & 0.34 & 3.07 \\
\hline & 5 & 3.04 & 1.53 \\
\hline & 6 & 3.89 & 6.83 \\
\hline & 7 & 1.34 & 5.34 \\
\hline & Mean & 2.02 & 6.35 \\
\hline \multirow[t]{8}{*}{24} & 1 & 3.24 & 4.92 \\
\hline & 2 & 1.51 & 22.71 \\
\hline & 3 & 1.65 & 6.66 \\
\hline & 4 & 1.55 & 1.48 \\
\hline & 5 & 0.00 & 1.63 \\
\hline & 6 & 2.61 & 4.55 \\
\hline & 7 & 0.02 & 5.08 \\
\hline & Mean & 1.51 & 6.72 \\
\hline \multirow[t]{8}{*}{31} & 1 & 3.57 & 5.51 \\
\hline & 2 & 2.70 & 2.73 \\
\hline & 3 & 2.06 & 2.94 \\
\hline & 4 & 0.06 & 1.66 \\
\hline & 5 & 0.00 & 3.19 \\
\hline & 6 & 3.09 & 5.19 \\
\hline & 7 & 0.61 & 3.92 \\
\hline & Mean & 1.73 & 3.59 \\
\hline
\end{tabular}

spring stiffnesses $K_{i j}$, and the positions of the support nodes $z_{\text {in }}$ and $z_{\text {out }}$ are given.

In the first step, the optimization is performed according to the model updating procedure described in section 3 with the 42 initial parameters listed in the first part of Table 3. From the outcomes listed in Table 4 it can be concluded that the natural frequencies are computed with sufficient accuracy with a mean error of $\epsilon_{E F}=2.02 \%$. However, the mean error of the mode shapes $\epsilon_{M S}=6.35 \%$ is not satisfying, particularly the representation of mode shape 2 by the FE model with $\epsilon_{M S}^{(2)}=17.78 \%$ is rather poor, which corresponds to a MAC value of 0.82 .

The comparison with the initial material parameters shows that the mean of the elasticity values $E_{1}^{l}, G_{12}^{l}$ and $G_{23}^{l}$ is slightly larger than the initial ones. For example, mean value of the moduli of elasticity in parallel $E_{1}$ is $12,426 \mathrm{MPa}$ compared to the initial value of $11,000 \mathrm{MPa}$, and the standard deviation with $1,320 \mathrm{MPa}$ is small, which shows that this parameter is similar for the individual panels. In contrast, the mean of the density is smaller than the initial value, while the spring stiffness values of the supports $K_{i j}$ remain roughly the same. The position of the inner support node $z_{\text {in }}=0.0594 \mathrm{~m}$ is larger than the initial value specified in Table 3, while the position of the outer support nodes $z_{\text {out }}=0.0277 \mathrm{~m}$ is less than the initial value. The rotational stiffness of the reinforced inner supports is therefore, as expected, larger than that of the outer supports.

However, the relatively large mean error of the mode shapes, especially for the second mode, leads to the assumption that the optimization algorithm is not able to find the global optimum due to the large number of optimization parameters. Therefore, the goal of the following sensitivity analysis is to identify parameters with minor influence in order to reduce the dimension of the optimization problem. The main focus here is on the elastic properties, since the parameters related to the boundary conditions of the supports are considered important. For the sensitivity analysis, each of the 28 parameters related to the material properties ( $E_{1}, G_{12}, G_{23}$ and $\rho$ for each slab) is individually increased by $20 \%$. Modal analysis results in modified modal properties $\tilde{f}_{i}$ and $\{\tilde{\phi}\}_{i}$. The relative changes in natural frequencies and mode shapes, evaluated by the MAC criterion, are shown in Fig. 12.

From Fig. 12(a) it can be concluded that by increasing the modulus of elasticity $E_{1}$ the natural frequencies change up to $2 \%$, with $E_{1}$ of panel 4 and 5 having the largest influence. $E_{1}$ of the panels 1 and 7 on the left and right edge of the flat slab have little influence on the natural frequencies. In terms of mode shapes, an increase in $E_{1}$ mainly changes the first mode shape, while higher modes remain almost unchanged. In the sensitivity study, the shear moduli $G_{12}$ and $G_{23}$ show a relatively similar behavior. As depicted in Figs. 12(b) and (c), the influence on the natural frequencies is negligible, and the change in mode shapes is only visible for the first mode. The density $\rho$ of the panels has the largest influence on the natural frequencies, where the change is up to $4.5 \%$, and on the mode shapes, see Fig. 12(d). Note the large influence of panel 4, where particularly the first two mode shapes are no longer correlated.

With this knowledge gained from this sensitivity analysis, the number of optimization parameters is reduced for further computations. Because of the small changes observed when using a set of parameters $E_{1}, G_{12}$ and $G_{23}$ for each panel individually, the next optimization will employ only one set for the entire slab. This reduces the number of parameters from 42 to 24. As can be seen in Table 4 (second part), the reduction in the number of parameters has only a minor effect on the natural frequencies, while the sum of the mean errors remains about the same as with 42 parameters. This also applies to the mode shape error, however for the second mode $\epsilon_{M S}^{(2)}$ even increasing to almost $23 \%$, or a MAC value of 0.77 accordingly. Compared to the model with 42 optimization parameters, the mean values of the shear moduli $G_{12}$ and $G_{23}$ and the mean value of the densities $\rho^{l}$ increase whereas the difference of the remaining parameters is negligible, see third part in Table 3 . 

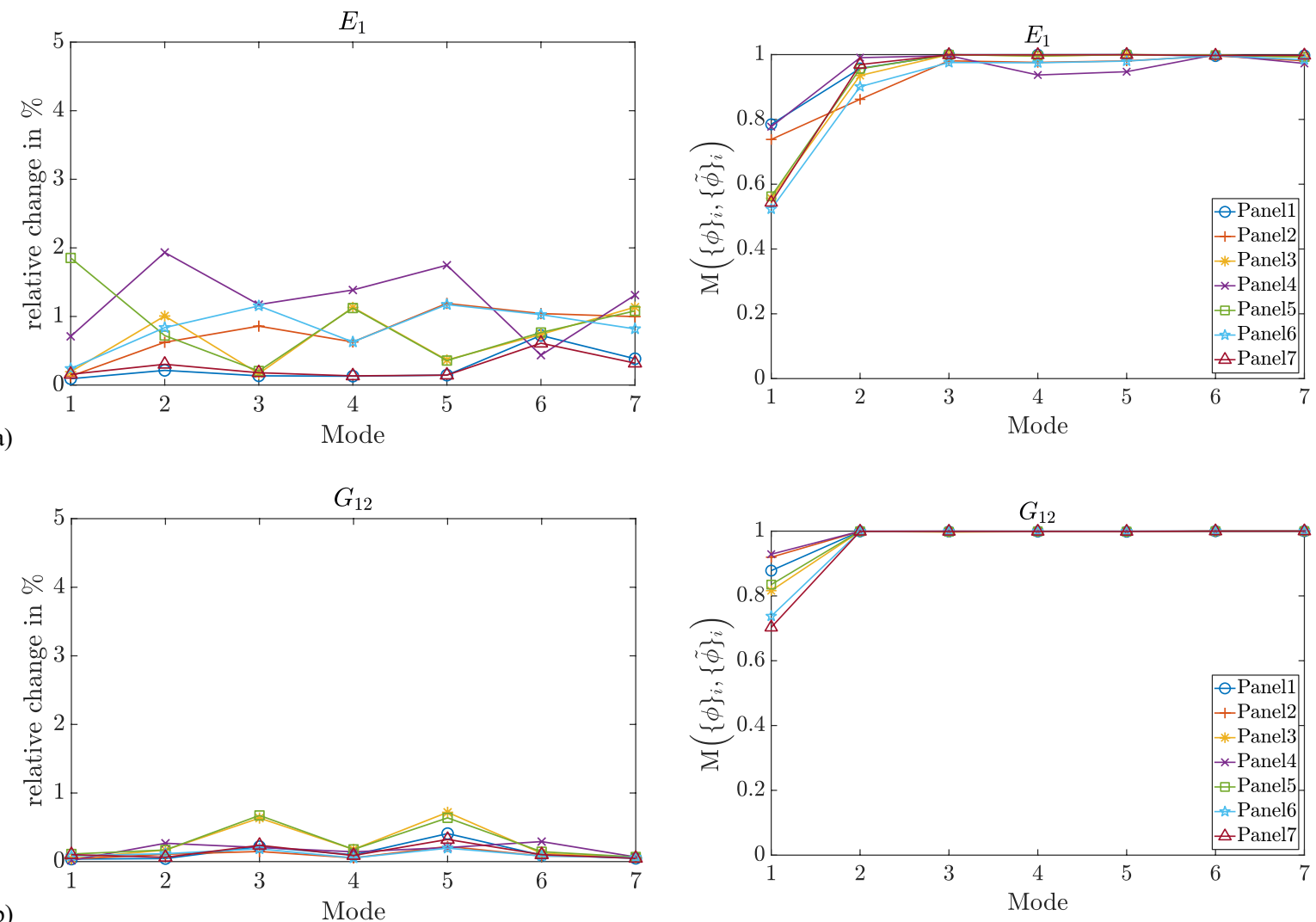

(b)
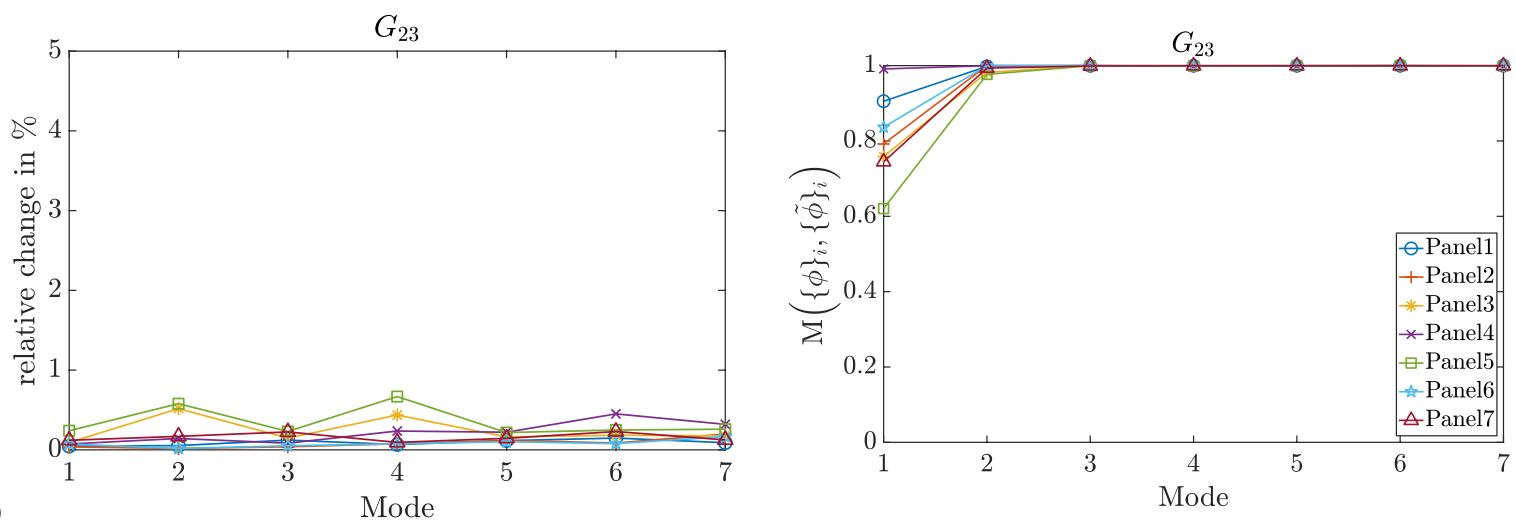

(c)
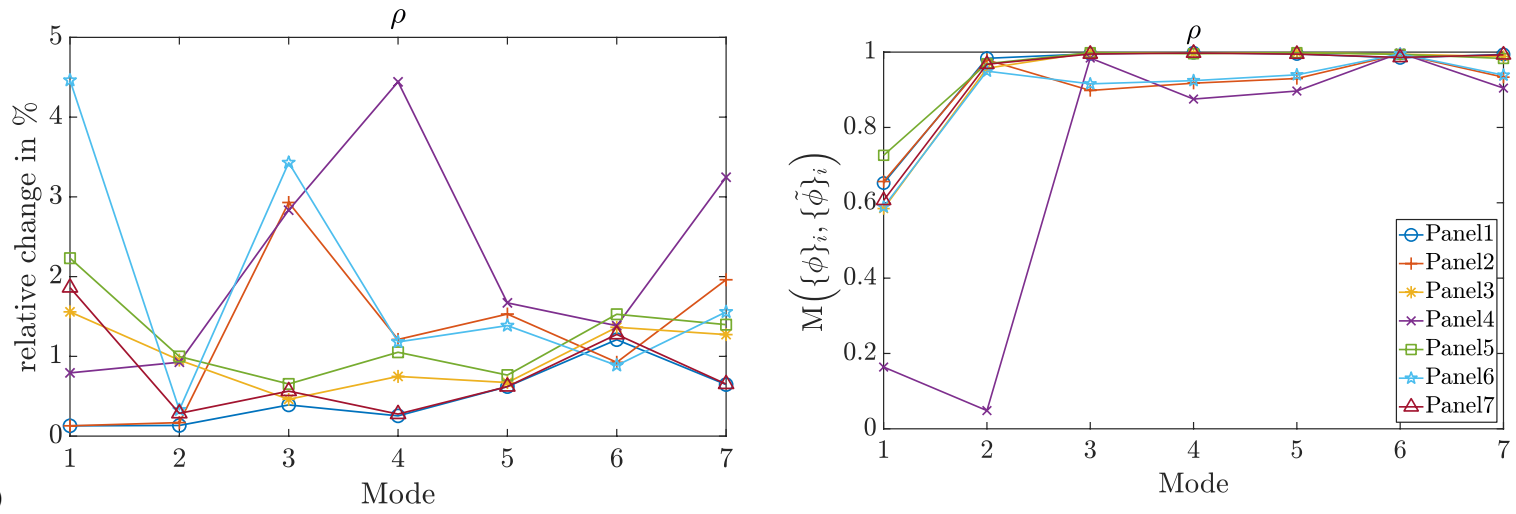

Fig. 12 Relative errors and MAC values of parameters from sensitivity analysis 


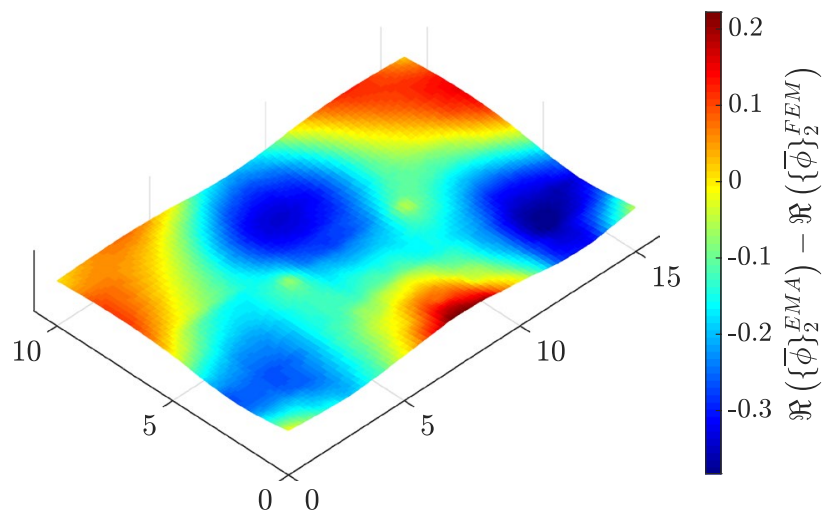

Fig. 13 Difference of experimentally and numerically obtained mode shape vectors for mode 2

To show the areas of the slab where experimental and numerical outcomes of the second mode shape differ, in Fig. 13 the difference between $\Re\{\bar{\phi}\}_{2}^{E M A}$ and $\Re\{\bar{\phi}\}_{2}^{F E M}$ (both normalized to a maximal value of 1 ) is illustrated. From this figure it can be concluded that with the current parameter set it is not possible to represent bending around the longitudinal symmetry axis with sufficient accuracy. Therefore, each plate is divided into an upper and a lower area with individual material properties. Considering the results presented so far, only density is treated as independent optimization parameter in both the upper and lower area of each panel, while the elastic properties $E_{1}, G_{12}$ and $G_{23}$ remain a single parameter set for the whole slab. This gives 31 parameters for the third optimization. This setup significantly reduces the MAC error for the second mode, as seen in Table 4 (bottom), while errors in the remaining mode shapes and the natural frequencies remain as low as in the previous optimizations. While the values of the elasticity parameters and the density are within the range of the optimization with 24 parameters, it is noteworthy that the distance of the inner support points increases compared to the two previously identified models, which indicates a significantly higher rotational stiffness of the two reinforced columns compared to the columns without any metallic fasteners (bottom part Table 3).

\subsubsection{Numerically identified modal parameters}

Based on these sensitivity studies, only 25 parameters are considered in the final optimization. These parameters are listed in Table 5. Modulus of elasticity $E_{1}$, shear modulus $G_{12}$ and rolling shear modulus $G_{23}$, which represent the first three parameters, are assigned to the entire slab. As can be seen in Table 5, the optimized values are between 11 and $15 \%$ higher than their initial values. The optimized density is different in each of the seven CLT panels of the slab. The upper and lower half of panel 4 must even be assigned different
Table 5 Initial and optimized parameters for the slab as well as the difference in $\%$

\begin{tabular}{|c|c|c|c|c|}
\hline Parameter & Unit & Initial & Optimized & Diff. [\%] \\
\hline$E_{1}$ & [MPa] & 11,000 & 12,268 & 11.5 \\
\hline$G_{12}$ & {$[\mathrm{MPa}]$} & 690 & 790 & 14.5 \\
\hline$G_{23}$ & [MPa] & 50.0 & 56.0 & 12.0 \\
\hline$\rho_{P 1}$ & {$\left[\mathrm{~kg} / \mathrm{m}^{3}\right]$} & 488 & 427 & -12.6 \\
\hline$\rho_{P 2}$ & {$\left[\mathrm{~kg} / \mathrm{m}^{3}\right]$} & 488 & 473 & -3.05 \\
\hline$\rho_{P 3}$ & {$\left[\mathrm{~kg} / \mathrm{m}^{3}\right]$} & 488 & 427 & -12.6 \\
\hline$\rho_{P 4 U}$ & {$\left[\mathrm{~kg} / \mathrm{m}^{3}\right]$} & 488 & 451 & -7.56 \\
\hline$\rho_{P 4 L}$ & {$\left[\mathrm{~kg} / \mathrm{m}^{3}\right]$} & 488 & 524 & 7.27 \\
\hline$\rho_{P 5}$ & {$\left[\mathrm{~kg} / \mathrm{m}^{3}\right]$} & 488 & 484 & -0.78 \\
\hline$\rho_{P 6}$ & {$\left[\mathrm{~kg} / \mathrm{m}^{3}\right]$} & 488 & 453 & -7.27 \\
\hline$\rho_{P 7}$ & {$\left[\mathrm{~kg} / \mathrm{m}^{3}\right]$} & 488 & 442 & -9.38 \\
\hline$K_{11}$ & {$[\mathrm{MN} / \mathrm{m}]$} & 50.0 & 63.0 & 26.1 \\
\hline$K_{12}$ & {$[\mathrm{MN} / \mathrm{m}]$} & 50.0 & 30.7 & -38.6 \\
\hline$K_{13}$ & {$[\mathrm{MN} / \mathrm{m}]$} & 50.0 & 30.7 & -38.6 \\
\hline$K_{14}$ & {$[\mathrm{MN} / \mathrm{m}]$} & 50.0 & 67.7 & 35.4 \\
\hline$K_{21}$ & {$[\mathrm{MN} / \mathrm{m}]$} & 50.0 & 57.8 & 15.5 \\
\hline$K_{22}$ & {$[\mathrm{MN} / \mathrm{m}]$} & 50.0 & 52.3 & 4.64 \\
\hline$K_{23}$ & {$[\mathrm{MN} / \mathrm{m}]$} & 50.0 & 60.0 & 20.0 \\
\hline$K_{24}$ & {$[\mathrm{MN} / \mathrm{m}]$} & 50.0 & 46.7 & -6.54 \\
\hline$K_{31}$ & {$[\mathrm{MN} / \mathrm{m}]$} & 50.0 & 50.8 & 1.56 \\
\hline$K_{32}$ & {$[\mathrm{MN} / \mathrm{m}]$} & 50.0 & 50.5 & 0.94 \\
\hline$K_{33}$ & {$[\mathrm{MN} / \mathrm{m}]$} & 50.0 & 49.2 & -1.60 \\
\hline$K_{34}$ & {$[\mathrm{MN} / \mathrm{m}]$} & 50.0 & 33.1 & -33.7 \\
\hline$z_{\text {in }}$ & {$[\mathrm{m}]$} & 0.05 & 0.0883 & 76.6 \\
\hline$z_{\text {out }}$ & {$[\mathrm{m}]$} & 0.05 & 0.0257 & -48.6 \\
\hline
\end{tabular}

densities (denoted as $\rho_{P 4 U}$ and $\rho_{P 4 L}$, respectively), while one density is sufficient for each of the other panels. The optimization yields values between 426.5 and $523.5 \mathrm{~kg} / \mathrm{m}^{3}$ for the density, with the highest value assigned to the lower part of panel 4. It should be noted that the shaker is located in this area of panel 4. The spring stiffnesses of the supports, $K_{11}$ to $K_{34}$, are within a range of 30.70 to $67.72 \mathrm{MN} / \mathrm{m}$ after optimization. These values correspond to a stiffness soil modulus $E_{s}$ of about 40 to $100 \mathrm{MN} / \mathrm{m}^{2}$, which represents the parameter range of the present medium-dense soil (Türke 1999). The final two parameters optimized are the distances of the modeled support node from the mid-surface, as outlined in sections 3.2 and 4.2.1. For the reinforced (inner) supports the optimization procedure yields the distance $z_{i n}=0.083 \mathrm{~m}$, and for the outer supports $z_{\text {out }}=0.0257 \mathrm{~m}$. These results are consistent with the additional rotational stiffness to be introduced by the steel reinforcements.

Table 6 lists among others the numerically computed natural frequencies based on the optimized parameters $\left(f_{i, O p t}^{F E M}\right)$ and the corresponding relative error measures $\epsilon_{E F, O p t}^{(i)}$, $\epsilon_{M S, O p t}^{(i)}$ with respect to the experimental data. Comparing the 
Table 6 Computed natural frequencies and relative modal errors based on the initial (subscript Init) and the optimized (subscript $O p t$ ) parameter set

\begin{tabular}{lllllll}
\hline $\begin{array}{l}\text { Mode } \\
(i)\end{array}$ & $\begin{array}{l}f_{i, \text { Init }}^{F E M} \\
{[\mathrm{~Hz}]}\end{array}$ & $\begin{array}{l}f_{i, O p t}^{F E M} \\
{[\mathrm{~Hz}]}\end{array}$ & $\begin{array}{l}\epsilon_{E F, \text { Init }}^{(i)} \\
{[\%]}\end{array}$ & $\begin{array}{l}\epsilon_{M S, \text { Init }}^{(i)} \\
{[\%]}\end{array}$ & $\begin{array}{l}\epsilon_{E F, O p t}^{(i)} \\
{[\%]}\end{array}$ & $\begin{array}{l}\epsilon_{M S, \text { Opt }}^{(i)} \\
{[\%]}\end{array}$ \\
\hline 1 & 10.40 & 10.93 & 1.08 & 30.27 & 4.03 & 5.49 \\
2 & 10.78 & 11.25 & 6.20 & 31.54 & 2.07 & 2.53 \\
3 & 15.28 & 15.92 & 2.08 & 5.57 & 2.04 & 4.95 \\
4 & 21.53 & 22.61 & 4.39 & 5.38 & 0.40 & 1.49 \\
5 & 22.62 & 24.26 & 6.78 & 2.80 & 0.02 & 1.88 \\
6 & 24.41 & 26.26 & 8.77 & 4.78 & 1.87 & 5.60 \\
7 & 29.55 & 31.69 & 6.76 & 5.17 & 0.00 & 4.25 \\
Mean & & & 5.15 & 12.22 & 1.49 & 3.74 \\
\hline
\end{tabular}

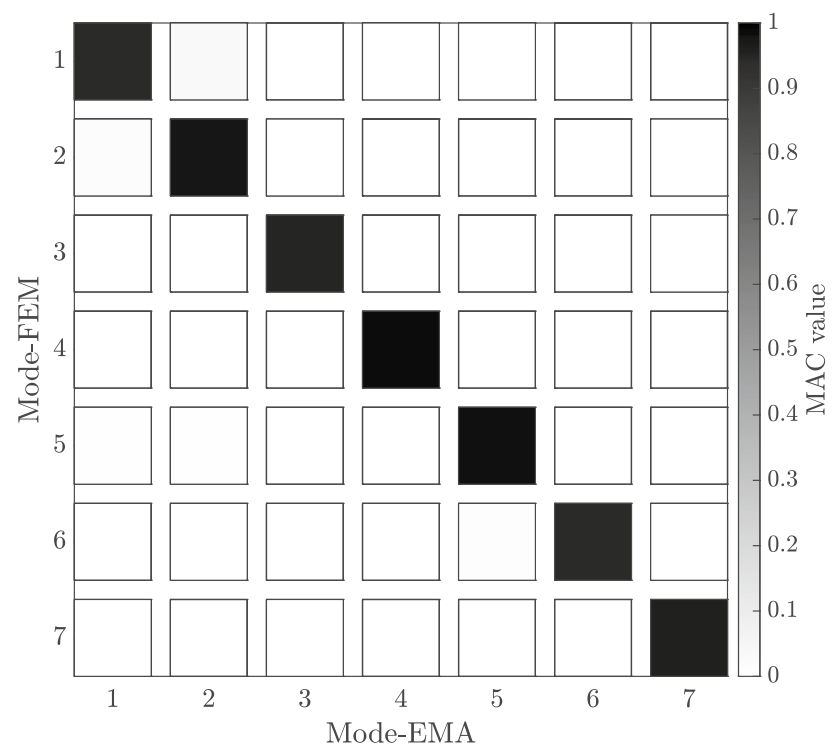

Fig. 14 MAC matrix between experimentally obtained and numerically computed mode shapes

errors for the optimized parameters with those given in Table 4 for the set of 31 parameters, it can be concluded that by reducing the number of parameters to 25 , the mean error in the natural frequencies is slightly reduced from $1.7 \%$ to $1.5 \%$, while the mean error in the mode shapes remains the same with $3.7 \%$. Figure 14, which shows graphically the components of the MAC matrix between experimentally and numerically obtained mode shapes after model updating, confirms the excellent correlation of both sets of mode shapes. To demonstrate the superiority of the optimized parameter set over the initial set, Table 6 additionally lists the natural frequencies $f_{i, \text { Init }}^{F E M}$ and the corresponding relative errors $\epsilon_{E F, \text { Init }}^{(i)}$ and $\epsilon_{M S \text {,Init }}^{(i)}$ when using the initial parameter set. As observed, using the optimized parameters reduces the average error for the calculated frequencies from $5.2 \%$ to $1.5 \%$. However, the greatest improvement is achieved in the mode shapes of the first two modes when using the optimized parameters. In contrast to the mode shapes based on

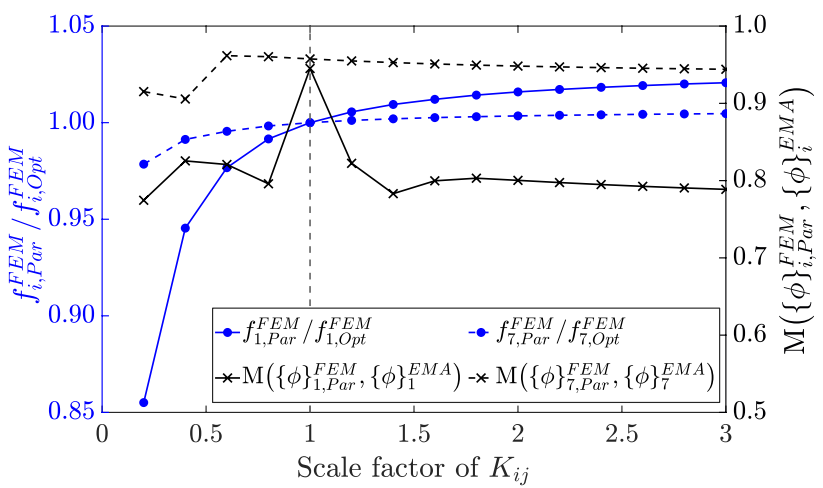

Fig. 15 Selected normalized natural frequencies and MAC values plotted against the support stiffness

the optimized parameters, the mode shapes based on the initial parameter set differ significantly from the experimental ones with errors $\epsilon_{E F \text {,Init }}^{(i)}(i=1,2)$ of about $30 \%$, whereas the corresponding maximum error for the optimized set is $5.49 \%$.

\subsubsection{Selected parameter studies}

After the numerical model has been calibrated by means of model updating with experimental data, numerous computations can be performed for parameter studies. To highlight the importance of the boundary conditions (specifically the support stiffness) for the predicted dynamic properties, a parameter study is carried out in which the optimized spring stiffnesses are varied. In addition, the effect of different spans by specific changes of the dimensions of the final model is investigated. Finally, the impact of two different layer setups on the dynamic properties of the point supported slab is studied.

For the first study, the spring stiffness values of the final model with optimized parameters (specified in Table 5) are uniformly scaled by a factor between 0.2 and 3.0. As a result of this study, the solid line with point-shaped markers of Fig. 15 shows the fundamental $\left(f_{1, P a r}^{F E M}\right)$ and the dashed line 
with point markers shows the highest $\left(f_{7, P a r}^{F E M}\right)$ considered natural frequency normalized with the corresponding frequency of the final model $\left(f_{i, O p t}^{F E M}, i=1,7\right)$. The corresponding MAC values between the numerically and the experimentally obtained modes are represented by lines with crossshaped markers. As expected, the influence of the boundary conditions on the fundamental frequency is much greater than on the natural frequencies of the higher modes. If the stiffness is $20 \%$ of the initial values, the fundamental frequency is only $86 \%$ of the value of the model with optimal parameters. By increasing the stiffness of the support by a factor of three, this frequency increases by about $2 \%$. In contrast, the normalized seventh natural frequency only varies in the range between 0.97 and 1.01. The sensitivity of the MAC value (which is an indicator for the shape of the mode) is also more pronounced for the fundamental mode than for the higher mode. However, the variation of the MAC value with respect to the stiffness scale factor is less uniform than for the corresponding frequency.

In the second parameter study, the span and thus the column grid is varied in the range of $\pm 20 \%$ from the initial value of $5 \mathrm{~m}$, i.e. the range between 4 and $6 \mathrm{~m}$ is considered. It should be noted that the slab with the largest column grid of $6.0 \times 6.0 \mathrm{~m}$ still meets the static demands. In the models with spans other than $5 \mathrm{~m}$, the number of steel plates used for the slab joints has been retained and only the length is scaled in accordance with the slab dimensions. The left graph of Fig. 16 shows the normalized first (solid line with point markers), third (solid line with circular markers), fourth (solid line with triangle-shaped markers) and seventh (dashed line with point markers) natural frequency as a function of the column grid. The three normalized frequencies not shown are bounded by the third and fourth normalized frequencies in the entire span range considered. In the right graph of Fig. 16, the corresponding MAC values between the numerically obtained mode shapes and the experimentally

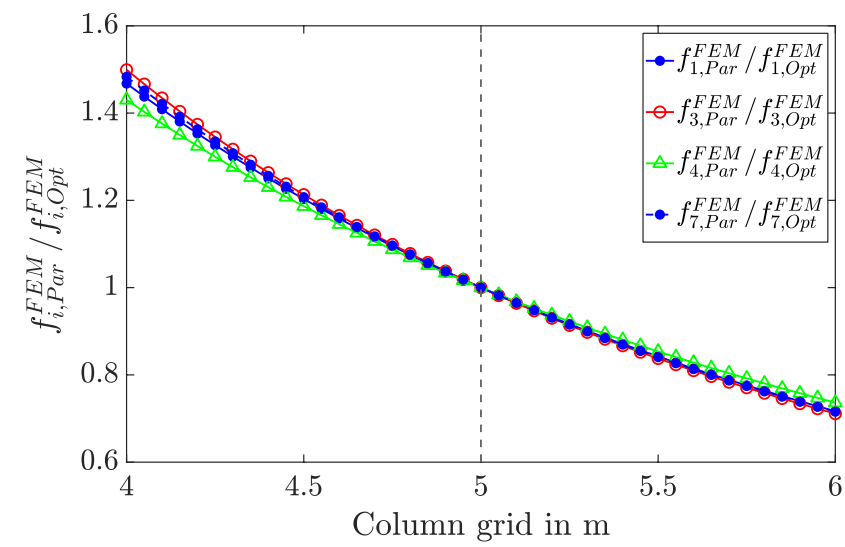

measured mode shapes are depicted. As observed, all considered normalized natural frequencies are about $45 \%$ above the values of the optimized slab model at the smallest considered span of $4 \mathrm{~m}$ and about $25 \%$ below at the largest span of $6 \mathrm{~m}$. The variation of the span has the same effect on all considered natural frequencies. In contrast, only the MAC values of the first mode shape are affected, while the influence of the span on the MAC values of the remaining modes is negligible. Changing the dimension can result in additional modes in the considered range of natural frequencies. However, this effect is not illustrated here since only the modes identified in the model with $5 \mathrm{~m}$ grid are studied.

In the last study the effect of two different layer setups on the identified natural frequencies and mode shapes is investigated. With a total thickness of $200 \mathrm{~mm}$ the overall dimensions are maintained, while the layer thicknesses and number of layers are varied. The different setups of the CLT panels are listed in Table 7, where layer setup 0 refers to the original setup. The layer thickness affects the components of the bending stiffness matrix $[D]$ (see section 3.2), therefore, the bending stiffness in the longitudinal direction differs more from that in the transverse direction than in the original structure.

Thus, the setup of the CLT plate has a quite significant impact on the fundamental frequency since the mode is a bending mode around the longitudinal axis, as depicted in the left graph of Fig. 17 where the natural frequencies are normalized with the corresponding optimized frequency.

Table 7 Layer setups used in the study

\begin{tabular}{lll}
\hline & Number of layers & Layer thickness [mm] \\
\hline Layer setup 0 & 7 & $20-40-20-40-20-40-20$ \\
Layer setup 1 & 7 & $30-30-30-20-30-30-30$ \\
Layer setup 2 & 5 & $40-40-40-40-40$ \\
\hline
\end{tabular}

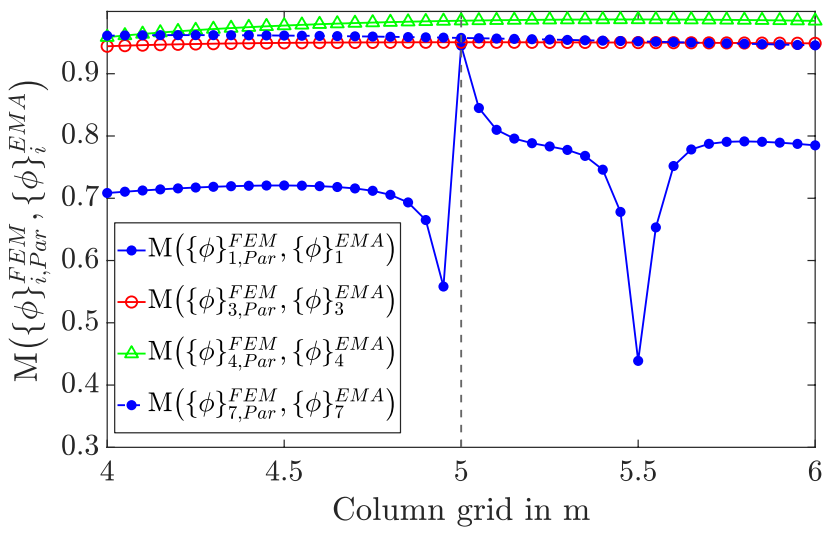

Fig. 16 Selected normalized natural frequencies (left graphs) and MAC values (right graphs) of models with different column grids 

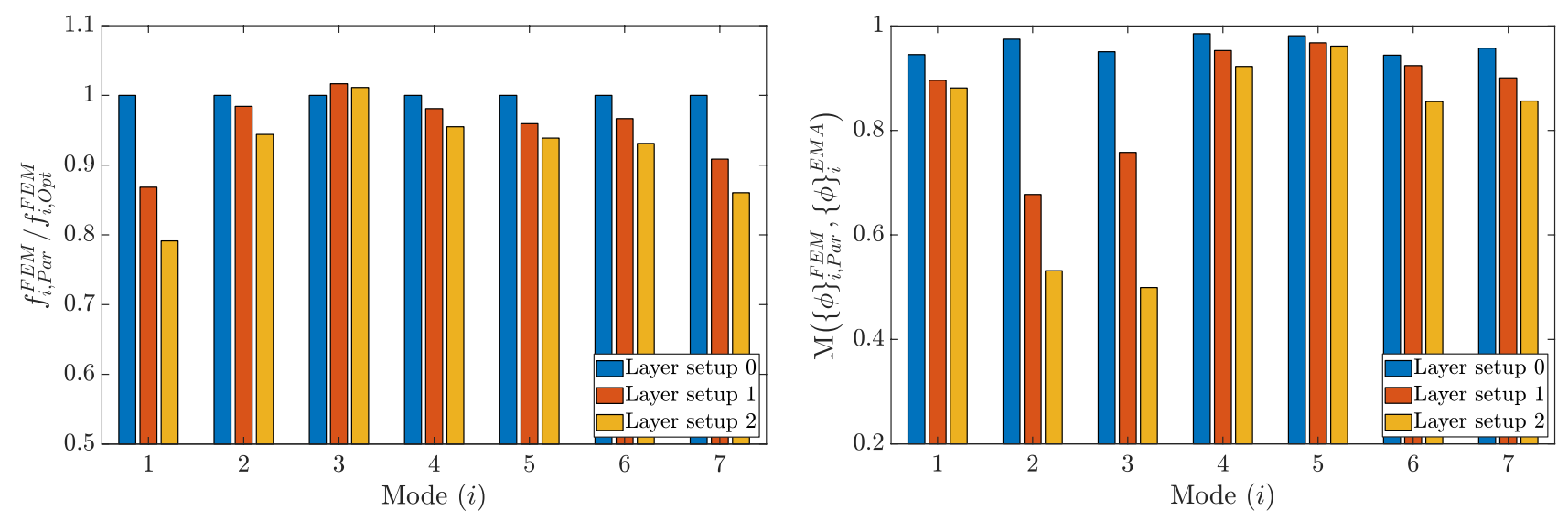

Fig. 17 Impact of different layer setups on the identified natural frequencies (left) and MAC values (right) compared to the initial layer setup 0

With the seven-layer setup 1, the fundamental frequency drops to about $86 \%$, while with the five-layer setup 2 this frequency is only $78 \%$ of the value of the original structure. The decrease in natural frequencies is observed in all identified modes except for the third mode which roughly corresponds to the optimized frequency. The MAC values of the alternative layer setups are shown in the right graph of Fig. 17. As observed, the MAC values of modes 2 and 3 decrease by $50 \%$ and more, while the impact on the remaining modes is less severe.

\section{Conclusion}

In this paper, the dynamic properties of a point-supported flat slab composed of seven CLT panels was investigated both experimentally and numerically. Based on the dynamic response at uniformly distributed 651 measuring points induced by a shaker, a detailed experimental modal analysis was performed.

An important conclusion of this study is that by identifying the fundamental frequency of $10.51 \mathrm{~Hz}$ the considered point-supported wide span panel with a column grid of $5.0 \mathrm{~m} \times 5.0 \mathrm{~m}$ and dimensions of $16.0 \mathrm{~m} \times 11.0 \mathrm{~m} \times 0.2 \mathrm{~m}$ will meet the serviceability criterion defined in Eurocode 5 (2019). Since this dimension of the panel is only possible with a new type of point support, it seems likely to extend the range of application of CLT for large-volume wide span structures. Note that in this study only the slab without floor construction was investigated. Clearly, depending on the additional mass, natural frequencies will decrease due to this construction.

As the measurements were taken over the course of two days, the identified modal properties exhibited a time dependence due to environmental effects. In modal parameter extraction, this led to complex mode shapes with unexpectedly high imaginary part. However, this disturbance effect could be successfully corrected by separate central axis rotations of the mode shape vector components corresponding to the different measurements. The experimental data were used in a model updating procedure to obtain parameters of a finite element model of the slab. This study therefore highlights the sensitivity of the parameter identification of CLT structures to environmental influences. These effects must be considered realistically when determining CLT parameters on the basis of non-destructive dynamic measurements.

It was shown that parameters related to both material properties and boundary conditions must be included to obtain a satisfactory agreement between experimental and numerical results. Since seven experimentally obtained modes were considered in the model updating procedure, the optimized parameters represent a robust set of data. Furthermore it was demonstrated how a set of poorly chosen parameters, which do not satisfactorily represent the prevailing boundary conditions and material parameters, have a significant impact on the results. Particularly computed modes with low natural frequencies do not correlate with the experimentally obtained modes.

The numerical model with the identified parameters serves as basis for numerical parameter studies in order to identify the sensitivity of the CLT slab to changes in the layer setup, geometry, boundary and matching conditions, and material properties. The three parameter studies presented show first the influence of different boundary conditions, specifically the support stiffness, second the influence of different spans on the natural frequencies and mode shapes and third the impact of different CLT layer setups on the dynamic properties.

Subsequently, the serviceability limit criteria regarding for example structure-borne noise and impact noise (which 
are often design-critical criteria for timber floors) for the considered type of CLT can be closely examined.

Funding Open access funding provided by University of Innsbruck and Medical University of Innsbruck.

Open Access This article is licensed under a Creative Commons Attribution 4.0 International License, which permits use, sharing, adaptation, distribution and reproduction in any medium or format, as long as you give appropriate credit to the original author(s) and the source, provide a link to the Creative Commons licence, and indicate if changes were made. The images or other third party material in this article are included in the article's Creative Commons licence, unless indicated otherwise in a credit line to the material. If material is not included in the article's Creative Commons licence and your intended use is not permitted by statutory regulation or exceeds the permitted use, you will need to obtain permission directly from the copyright holder. To view a copy of this licence, visit http://creativecommons.org/licenses/by/4.0/.

\section{References}

Abaqus (2015) ABAQUS/Standard User's Manual, Version 2016. Dassault Systèmes

Allemang RJ (2003) The modal assurance criterion - twenty years of use and abuse. Sound Vibr 37:14-21

Berner M, Gier J, Scheffler M, Hardtke H (2007) Identifikation von Werkstoffparametern an Platten aus Holz und Holzwerkstoffen mittels Modalanalyse [Identification of material parameters on panels made of wood and wood-based materials using modal analysis]. Holz Roh- Werkst 65(5):367-375 (in German)

Brandner R, Flatscher G, Ringhofer A, Schickhofer G, Thiel A (2016) Cross laminated timber (CLT): overview and development. Eur J Wood Prod 74(3):331-351

Cauberghe B, Guillaume P, Verboven P, Vanlanduit S, Parloo E (2005) On the influence of the parameter constraint on the stability of the poles and the discrimination capabilities of the stabilisation diagrams. Mechan Syst Signal Process 19(5):989-1014

DIN 1052 (2004) Design of timber structures - General rules and rules for buildings. Standard, DIN Deutsches Institut für Normung e.V

Eurocode 5 (2019) EN 1995-1-1: Design of timber structures - Part 1-1: General - Common rules and rules for buildings. Standard

Ewins DJ (2000) Modal Testing: Theory, Practice, and Application, 2nd edn. Mechanical engineering research studies, Research Studies Press

Forest Products Laboratory (2010) Wood handbook: wood as an engineering material. Forest products, Madison, WI

Friswell MI, Mottershead JE (1995) Finite element model updating in structural dynamics, Solid Mechanics and its Applications, vol 38. Kluwer Academic Publishers

Furtmüller T, Adam C (2020) An accurate higher order plate theory for vibrations of cross-laminated timber panels. Comp Struct 239:112017

Furtmüller T, Kawrza M, Adam C (2019) Experimentelle und numerische Modalanalyse von Brettsperrholzbalken zur Erfassung von Materialschädigung [Experimental and numerical modal analysis of cross laminated timber beams to identify material damage]. In: Proc. 16. D-A-CH Tagung Erdbebeningenieurwesen \& Baudynamik (D-A-CH 2019), Innsbruck, Austria (in German)

von Gierke H, Brammer A (2010) Harris' shock and vibration handbook - Effects of shock and vibration on humans. McGraw-Hill, New York
Görlacher R (1984) Ein neues Messverfahren zur Bestimmung des Elastizitätsmoduls von Holz [A new measuring method for determining the modulus of elasticity of wood]. Holz Roh- Werkst 42(6):219-222 (in German)

Griffin MJ (1990) Handbook of human vibration. Academic Press, London San Diego

Gsell D, Feltrin G, Schubert S, Steiger R, Motavalli M (2007) Crosslaminated timber plates: Evaluation and verification of homogenized elastic properties. J Struct Eng 133(1):132-138

Gülzow A, Gsell D, Steiger R (2008) Zerstörungsfreie Bestimmung elastischer Eigenschaften quadratischer 3-schichtiger Brettsperrholzplatten mit symmetrischem Aufbau [Non-destructive determination of elastic properties of square 3-layer cross laminated timber plates with symmetric layer setup]. Holz Roh- Werkst 66(1):19-37 (in German)

Hamm P, Richter A, Winter S (2010) Floor vibrations-new results. In: Proc. 11th World Conference on Timber Engineerig (WCTE2010), Riva del Garda, Italy

Kreuzinger H, Mohr B (1999) Gebrauchstauglichkeit von Wohnungsdecken aus Holz: Abschlußbericht [Serviceability of wooden floors: Final report]. Fraunhofer-IRB-Verlag (in German)

Maderebner R (2018) Connecting device for mounting a wooden construction element. US20180371741 (A1), 2018-12-27

MATLAB (2019) User's Guide R2019a. The MathWorks Inc., Natick, Massachusetts

Maurer B, Maderebner R, Zingerle P, Färberböck I, Flach M (2018) Point-supported flat slabs with CLT panels. In: Proc. 15th World Conference on Timber Engineering (WCTE2018), Seoul, Korea

Muster M, Frangi A (2020) Experimental analysis and structural modelling of the punching behaviour of continuous two-way CLT flat slabs. Eng Struct 205:110046

Niemz P, Sonderegger WU (2017) Holzphysik: Physik des Holzes und der Holzwerkstoffe [Wood physics: Physics of wood and woodbased materials]. Fachbuchverlag Leipzig im Carl Hanser Verlag (in German)

ÖNORM B 1995-1-1, (2019) Eurocode 5: Design of timber structures Part 1-1: General - Common rules and rules for buildings. Standard, Austrian Standards International

ÖNORM EN 338, (2016) Structural timber - Strength classes. Standard, Austrian Standards Institute

ÖNORM EN 408, (2012) Timber structures-structural timber and glued laminated timber-Determination of some physical and mechanical properties. Standard, Austrian Standards Institute

Phillips AW, Allemang RJ (2014) Normalization of Experimental Modal Vectors to Remove Modal Vector Contamination. In: Topics in Modal Analysis II, Volume 8, Springer International Publishing, pp 29-41

Popovski M, Chen Z, Gafner B (2016) Structural behaviour of pointsupported CLT floor systems. In: Proc. 14th World Conference on Timber Engineering (WCTE2016), Vienna, Austria

Rasmussen G (1982) Human body vibration exposure and its measurement. Brüel\&Kjær Technical Paper No 1

Reddy JN (2004) Mechanics of laminated composite plates and shells: theory and analysis, 2nd edn. CRC Press

Schickhofer G, Bogensperger T, Augustin M, Graz TU, HolzBauForschungs-GmbH (eds) (2010) BSPhandbuch: Holz-Massivbauweise in Brettsperrholz; Nachweise auf Basis des neuen europäischen Normenkonzepts [CLT handbook: Solid wood construction in cross laminated timber; Verifications based on the new European standards], 2nd edn. Verl, TU Graz (in German)

Steiger R, Gülzow A, Czaderski C, Howald M, Niemz P (2012) Comparison of bending stiffness of cross-laminated solid timber derived by modal analysis of full panels and by bending tests of strip-shaped specimens. Eur J Wood Prod 70(1-3):141-153

Türke H (1999) Statik im Erdbau [Earthwork Statics], 3rd edn. Ernst, Berlin (in German) 
Verboven P (2002) Frequency-domain system identification for modal analysis. Ph.D. thesis, Department of Mechanical Engineering, Vrije Universiteit Brussel

Weckendorf J, Toratti T, Smith I, Tannert T (2016) Vibration serviceability performance of timber floors. Eur J Wood Prod 74(3):353-367

Whitney JM (1973) Shear correction factors for orthotropic laminates under static load. J Appl Mechan 40(1):302-304

Wolf J (1994) Foundation Vibration Analysis Using Simple Physical Models. Prentice Hall
Publisher's Note Springer Nature remains neutral with regard to jurisdictional claims in published maps and institutional affiliations. 